\author{
Economics Working Paper Series
}

2017/018

\title{
Fiscal policy shocks and stock prices in the United States.
}

Haroon Mumtaz and Konstantinos Theodoridis

The Department of Economics

Lancaster University Management School

Lancaster LA1 4YX

UK provided that full acknowledgement is given. 


\title{
Fiscal policy shocks and stock prices in the United States.*
}

\author{
Haroon Mumtaz ${ }^{\dagger}$ \\ Queen Mary University
}

\author{
Konstantinos Theodoridis ${ }^{\ddagger}$ \\ Bank of England \\ Lancaster University Management School
}

June 2017

\begin{abstract}
This paper uses a range of structural VARs to show that the response of US stock prices to fiscal shocks changed in 1980. Over the period 1955-1980 an expansionary spending or revenue shock was associated with modestly higher stock prices. After 1980, along with a decline in the fiscal multiplier, the response of stock prices to the same shock became negative and larger in magnitude. We use an estimated DSGE model to show that this change is consistent with a switch from an economy characterised by active fiscal policy and passive monetary policy to one where fiscal policy was passive and the central bank acted aggressively in response to inflationary shocks.
\end{abstract}

Key words: Fiscal policy shocks, Stock prices, VAR, DSGE.

JEL codes: C5, E1, E5, E6

\section{Introduction}

Central banks around the world have tried to counter the impact of the Great Recession by resorting to ultra-low interest rates and unconventional monetary policy. However, the effectiveness of unconventional policy in supporting the real economy has been questioned in the recent literature. For example, in a panel study Gambacorta et al. (2014) conclude that 'in order to bring about a significant monetary stimulus a massive expansion of central banks balance sheets is required'. In contrast, there is some evidence that such policies may have a significant impact on asset prices such as stock prices (see Swanson $(2015 \mathrm{~b})$ ), with possible adverse consequences for the distribution of income and consumption (see Mumtaz and Theophilopoulou $(2016)$ ).

If it is indeed the case that unconventional monetary policy influences asset prices without a large impact on the aggregate economy, then the case for reconsidering the role of fiscal policy becomes stronger. This consideration makes it important to investigate the transmission of fiscal policy shocks to the real economy and asset prices.

As far as the real effects of fiscal policy are concerned, there is an extensive and growing literature on estimating the multiplier of US output to government spending and taxation shocks. Recent examples include Mertens and Ravn (2014) and Mertens and Ravn (2013) who build on

\footnotetext{
*Any views expressed are solely those of the author(s) and so cannot be taken to represent those of the Bank of England or to state Bank of England policy. This paper should therefore not be reported as representing the views of the Bank of England or members of the Monetary Policy Committee, Financial Policy Committee or Prudential Regulation Authority Board.

${ }^{\dagger}$ Email:h.mumtaz@qmul.ac.uk

${ }^{\ddagger}$ konstantinos.theodoridis@bankofengland.co.uk
} 
earlier contributions of Mountford and Uhlig (2009), Ramey (2011) and Blanchard and Perotti (2002) amongst numerous others and show that these shocks have a significant impact. Papers such as Perotti (2005), however, have shown that the fiscal multipliers have declined in magnitude after 1980.

The issue of the transmission of fiscal shocks to asset prices such as stock prices has received far less attention from the empirical side. Two recent contributions include Afonso and Sousa (2011) and Chatziantoniou et al. (2013). Using an an extended version of the Vector Autoregression (VAR) of Blanchard and Perotti (2002), they show that positive (negative) shocks to government spending (taxes) lead to a fall (rise) in stock prices in the US. However, Afonso and Sousa (2011) do not include any proxy for monetary policy in their VAR model, an omission criticised by Chatziantoniou et al. (2013).1 These authors examine the impact of government spending on an expanded version of the VAR used by Afonso and Sousa (2011). The find that over the period spanning 1991 to 2010, Government spending shocks appear to have little impact on real and financial variables. However, their relatively small sample excludes important innovations in fiscal variables during the 1970s and the early 1980s and it is unclear if their conclusions are robust to using a longer span of data.

The current paper extends this literature along three dimensions. First, we provide VAR results on the transmission of US government and taxation shocks to real stock prices that are robust across different shock identification schemes, thus departing from earlier papers that use one method of identifying fiscal shocks. Second and more importantly, we show that there is a change in the sign and magnitude of the response of stock prices to fiscal shocks after 1980 - expansionary fiscal policy shocks were associated with a modest increase in the stock price before 1980, while after this date the same policy is associated with large declines. Although previous papers have documented a decline in the magnitude of the fiscal multiplier across these sub-samples, to our knowledge, our study is the first to highlight the change in the response of stock prices to fiscal shocks. Finally, in order to explain the possible source of the change in the response of stock prices, we present a DSGE model - following Traum and Yang (2011), we augment the model developed by Christiano et al. (2005) and Smets and Wouters (2007) with a simple non-productive government sector. Estimation of this DSGE model pre and post-1980 reveals important changes in the behaviour of policy makers. In particular, we estimate that monetary policy was passive and fiscal policy was active during the period between 1955Q4 and 1979Q4. The lack of sufficient response to inflation by monetary authorities caused inflation expectations to rise after an expansionary fiscal shock resulting in a decrease in the real interest rate. As a consequence, investment and consumption rose pushing up equity prices. After 1980, our results suggest that both monetary and fiscal authorities set policy in a manner that was consistent with their objectives of stabilising inflation and public debt, respectively. These policies suppressed inflation expectations after an expansionary fiscal shock, causing the real rate to rise and equity prices to fall. While previous research has highlighted the possibility of changes in fiscal and monetary policy activism (see Leeper (1991) and Bianchi and Ilut (2014)), our paper shows that this shift may be a factor behind the changing response of stock prices to fiscal shocks. Therefore, our paper contributes to the literature linking changes in policy to the stock market (see Blanchard $(\overline{1981)}$ for a seminal paper and Galí and Gambetti (2015) for a recent analysis). While the focus of Galí and Gambetti (2015) is on the changing effects of monetary policy shocks, our contribution is to show that the impact of fiscal shocks on the stock market has been subject to a large shift.

The paper is organised as follows: The empirical results based on VAR models are presented in section 2. Section 3 introduces the theoretical model and discusses the parameter estimates. Section 4 concludes.

\footnotetext{
${ }^{1}$ Using a panel regression, Ardagna $(2009)$ report similar results-stock prices rise around periods of fiscal tightening.
} 


\section{Empirical Analysis}

We estimate the following VAR model for the United States:

$$
Y_{t}=\alpha \tau_{t}+\sum_{j=1}^{4} \beta_{t-j} Y_{t-j}+v_{t}
$$

where $\operatorname{var}\left(v_{t}\right)=\Omega$. $Y_{t}$ is a $N \times T$ matrix of endogenous variables while $\tau_{t}$ is matrix of exogenous variables included in the specification. The benchmark model includes the following seven endogenous variable: (1) Real per-capita government spending $\left(G_{t}\right),(2)$ Real per-capita GDP $\left(Y_{t}\right),(3)$ CPI inflation $\left(\pi_{t}\right)$, (4) Real per-capita government revenue $\left(T_{t}\right),(5)$ a short-term interest rate $\left(R_{t}\right)$, (6) the 10-year government bond yield $\left(I_{t}\right)$ and $(7)$ real stock prices $\left(S_{t}\right)$. All variables except inflation and the interest rates are included in log levels. Following, Perotti (2005), the fiscal variables are defined net of transfers and interest payments (see section 2.2). After $2008 \mathrm{Q} 4, R_{t}$ is proxied by the shadow interest rate estimated by $\mathrm{Wu}$ and Xia (2014). This provides a simple way to account for the zero lower bound (ZLB). We also verify below that our results are robust to truncating the sample before 2008. The exogenous variables in the model include a constant, a linear trend, a quadratic trend and a dummy variable for 1975Q2 (see Blanchard and Perotti (2002)).

\subsection{Identification of fiscal shocks}

The covariance matrix of reduced form shocks $\Omega$ can be decomposed as $\Omega=A_{0} A_{0}^{\prime}$. We use four approaches to estimate the contemporaneous impact matrix $A_{0}$ and identify government spending and taxation shocks. Our starting point is a simple recursive strategy as described in Caldara and Kamps (2008). The ordering of the variables is as listed above with the implication that government spending is not affected contemporaneously by macroeconomic or financial shocks but taxes respond immediately to shocks to $G_{t}, Y_{t}$ and $\pi_{t}$ i.e. innovations that may affect tax receipts. Both fiscal shocks are assumed to affect the fast moving variables, i.e. interest rates and stock prices, immediately. The second identification strategy follows the procedure devised in Blanchard and Perotti (2002) and extended to systems involving nominal variables in Perotti (2005). Their method involves using external information to calibrate the output, inflation and interest rate elasticity of government spending and taxation. Perotti (2005) estimates the output and inflation elasticity of taxes to be 1.85 and 1.25 respectively ${ }^{2}$ The output elasticity of government spending is set to zero as $G_{t}$ is defined net of transfers and not affected by business cycle fluctuations contemporaneously. The inflation elasticity of $G_{t}$ is set to -0.5 . Perotti $(2005)$ argues that an increase in inflation leads to a reduction in wages of government employees in real terms. As wages form a large proportion of spending, the elasticity is negative. As $G_{t}$ and $T_{t}$ are defined net of interest payments, their interest elasticity is set to zero. As in the recursive scheme, we also assume that $G_{t}$ and $T_{t}$ do not react contemporaneously to shocks to the long-term interest rate and stock prices. These restrictions, together with the assumption that spending decisions precede decisions on taxes results in an identified structural VAR (SVAR). The third identification scheme is based on the seminal work of Mountford and Uhlig (2009) who use sign restrictions to identify spending and revenue shocks. Following these authors, positive shocks to these variables are assumed to increase spending and revenue for four quarters. In addition, these shocks are assumed to be orthogonal to a business cycle shock that moves taxes and output in the same direction for four quarters. The final identification scheme relies on narrative measures of tax and spending shocks. These proxies

\footnotetext{
${ }^{2}$ Perotti (2005) also provides the estimates of these elasticities pre and post-1980. We also use these sub-sample estimates in our application of this model.
} 
can be added to the VAR directly or used as external instruments to estimate the appropriate column of $A_{0}$ (see Stock and Watson (2008)). Mertens and Ravn (2012) have recently introduced a refined version of the tax shock estimated by Romer and Romer (2010). Romer and Romer (2010) build their shock measure by purging legislated tax changes from movement that are endogenous and driven by policy makers' concerns about growth. However, Mertens and Ravn (2012) argue that the Romer and Romer (2010) tax shock may not satisfy exogeneity as the proxy does not account for implementation lags. Mertens and Ravn (2012) propose a proxy based on exogenous tax changes where legislation and implementation are less than a quarter apart. In related work, Ramey (2011) proposes a measure for news in government defence spending, an estimate of the expected discounted value of $G_{t}$ due to foreign political events. We use the Mertens and Ravn (2012) measure of tax changes as an instruments in a proxy SVAR to identify unanticipated tax shocks. In addition we attempt to capture anticipated changes in spending by using the Ramey (2011) news measure as an instrument for the spending shock.

The estimation of these three SVAR models is now standard in the literature. We, therefore, confine estimation details to the on-line technical appendix.

\subsection{Data and estimation samples}

We follow Perotti (2005) closely in defining government spending and net taxes. Government spending is defined as the sum of government consumption and investment. Net taxes are calculated as current receipts of the government less interest and transfer payments. Both variables are deflated by the GDP deflator and divided by total population. A full description of data sources and calculations is provided in Appendix A.

The benchmark sample runs from 1955Q1 to 2015Q4. When the Proxy VAR is employed the sample is altered slightly. Data for the Mertens and Ravn (2012) instrument is available until 2006Q4, while the series constructed by Ramey (2011) runs until 2013Q4.

Perotti (2005) provides strong evidence that the transmission of fiscal shocks has changed after 1980. The estimates presented in Perotti (2005) suggest that the response of output to fiscal shocks is smaller after 1980. Similar results are reported by Bilbiie et al. (2008) who suggest that a change in monetary policy and asset market participation may have played a role. Given this evidence, we estimate our models over the full sample and present results over the two sub-samples, before and after 1979Q4. We show below that very similar results are obtained if, instead of splitting the sample, we allow the parameters of the VAR to change over time. 

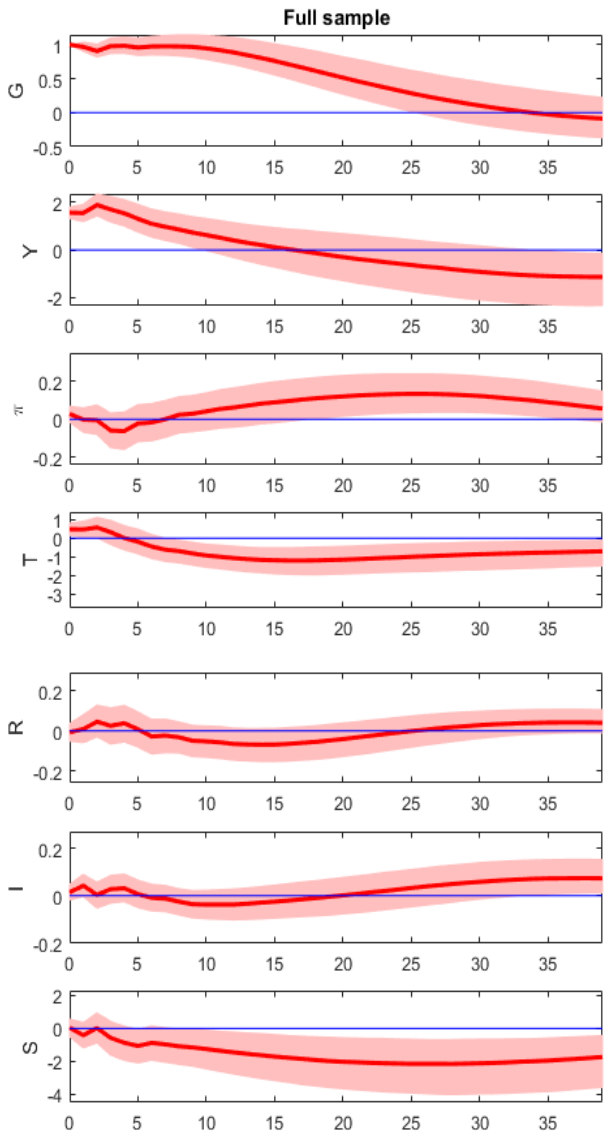

Pre-1980
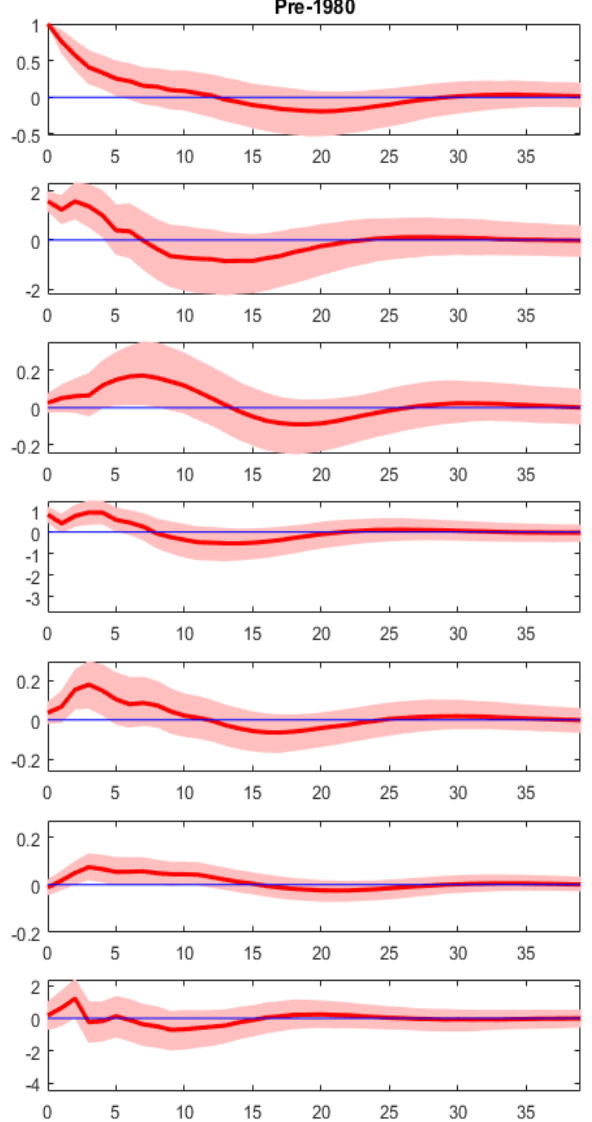

Post-1980
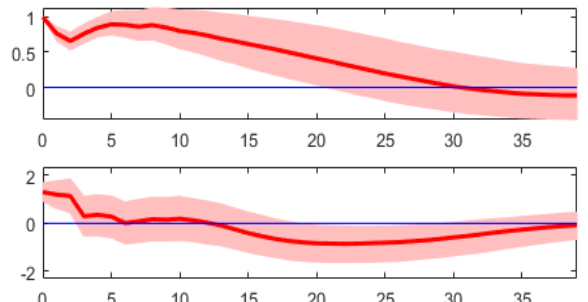

0.2
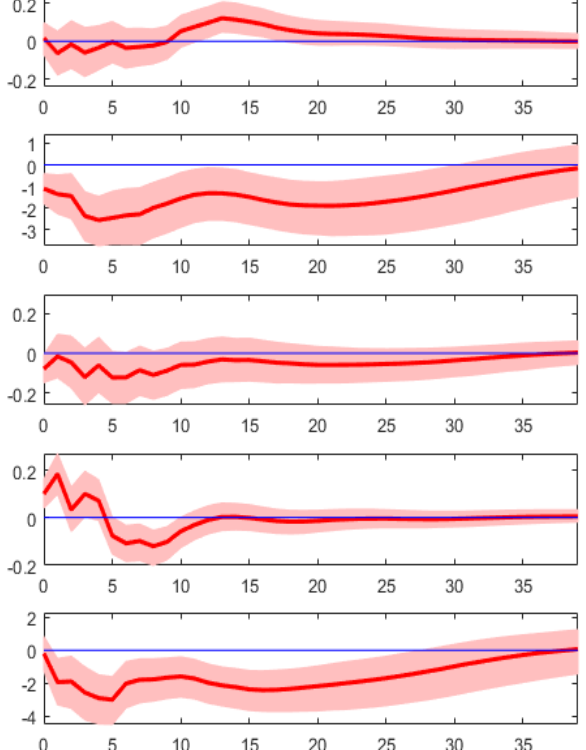

Figure 1: Percentage response to a Government Spending shock using the benchmark identification. The solid lines are median responses while the shaded area is the $68 \%$ error band. The Y-Axis labels are as follows: $(1)$ Real per-capita government spending $\left(G_{t}\right),(2)$ Real per-capita GDP $\left(Y_{t}\right),(3)$ CPI inflation $\left(\pi_{t}\right)$, (4) Real per-capita government revenue $\left(T_{t}\right)$, (5) a short-term interest rate $\left(R_{t}\right)$, $(6)$ the 10-year treasury bill rate $\left(I_{t}\right)$ and $(7)$ real stock prices $\left(S_{t}\right)$ The response of $Y$ is expressed as a multiplier. 

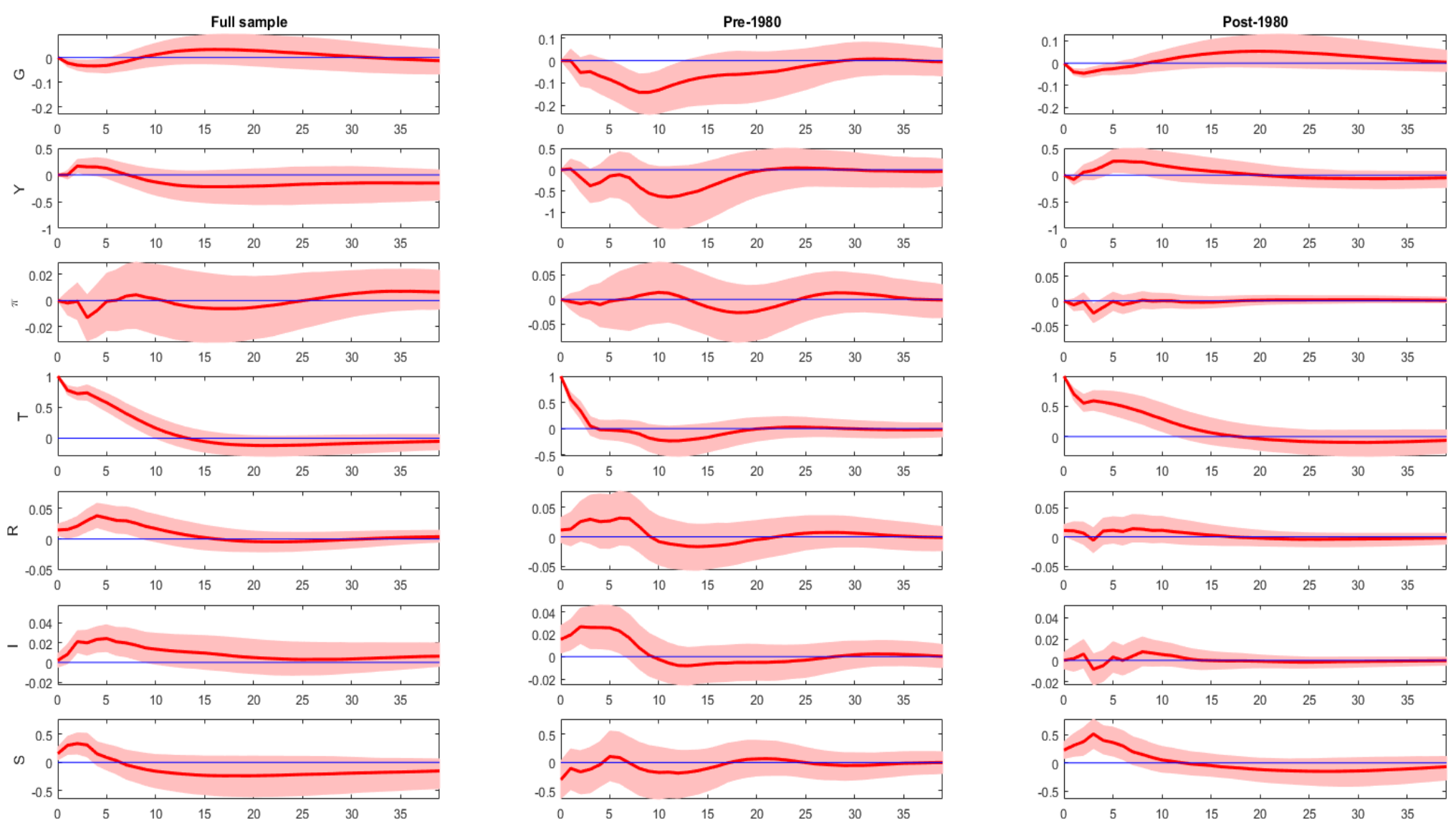

Figure 2: Percentage response to a government revenue shock using the benchmark identification. The solid lines are median responses while the shaded area is the $68 \%$ error band. The Y-Axis labels are as follows: (1) Real per-capita government spending $\left(G_{t}\right),(2)$ Real per-capita GDP $\left(Y_{t}\right),(3)$ CPI inflation $\left(\pi_{t}\right)$, (4) Real per-capita government revenue $\left(T_{t}\right)$, (5) a short-term interest rate $\left(R_{t}\right)$, $(6)$ the 10-year treasury bill rate $\left(I_{t}\right)$ and $(7)$ real stock prices $\left(S_{t}\right)$ The response of $Y$ is expressed as a multiplier. 

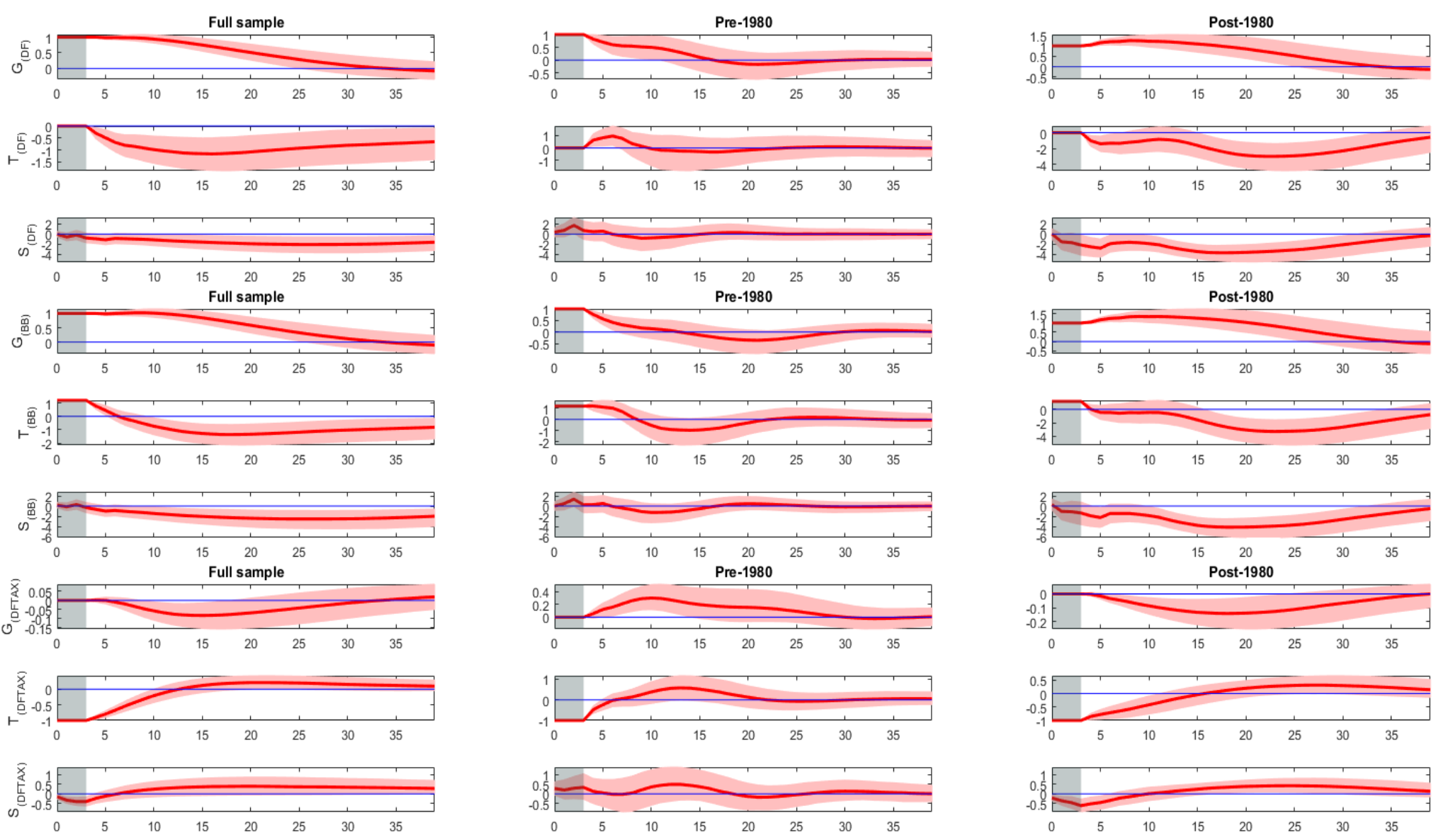

Figure 3: Policy experiments. DF refers to a deficit financed increase in $G$. BB refers to a balanced budget increase in $G$. DFTAX refers to a decrease in $T$ which deficit financed. The shaded area represents the horizon over which these restrictions are imposed. 


\section{$2.3 \quad$ Results}

\subsubsection{Impulse response of stock prices to fiscal shocks}

Figure 1 presents the response of the endogenous variables to a spending shock that raises $G$ by $1 \%$ using the recursive identification scheme. We treat these results as a simple benchmark and discuss the estimates from the alternative identification schemes below. The response of $Y$ is expressed in terms of a dollar change in GDP as a ratio of a dollar change in spending. Over the full sample, the output multiplier is estimated to be about 1.6 at the one year horizon, a magnitude consistent with results reported in Perotti (2005). As in Perotti (2005), there is evidence for a decline in the multiplier with the GDP response substantially less persistent in the post-1980 period. A similar result holds for inflation and the short-term interest rate - while these variables rise on impact during the pre-1980 period, the hypothesis of a zero response cannot be rejected in the post-1980 period. The short-term interest rate declines in response to the shock in all three sub-samples providing further support for the estimates in Perotti (2005). In contrast, the short-term increase in the $I_{t}$ is larger in the post-1980 period. Over both sub-samples, the initial increase in spending is not matched by a correponding rise in tax revenue. This aspect is more apparent in the second sub-sample where taxes show a decline in response to the shock ${ }^{3}$ Over the full sample, real stock prices show a persistent decline in response to this shock. However this hides a substantial change across the two subsamples. In the pre-1980 period, stock prices increase by about $1 \%$ at the 6 month horizon. In contrast, the response in the post-1980 period is characterised by a protracted decline which reaches about $3 \%$ at the one year horizon. The last row of Figure 2 shows that the stock price response to tax shocks also displays substantial variation across the two sub-samples. Before 1980, stock prices show a modest decline in response to a rise in taxes. After 1980, the response switches sign and stock prices rise by $0.5 \%$. The remaining responses display the pattern reported in earlier studies such as Perotti (2005) - for e.g. the response of output shows a decline in magnitude, with the drop in output in response to tax shocks reversing within two quarters after 1980.

\footnotetext{
${ }^{3}$ We consider policy experiments below where either $G$ or $T$ is held fixed.
} 

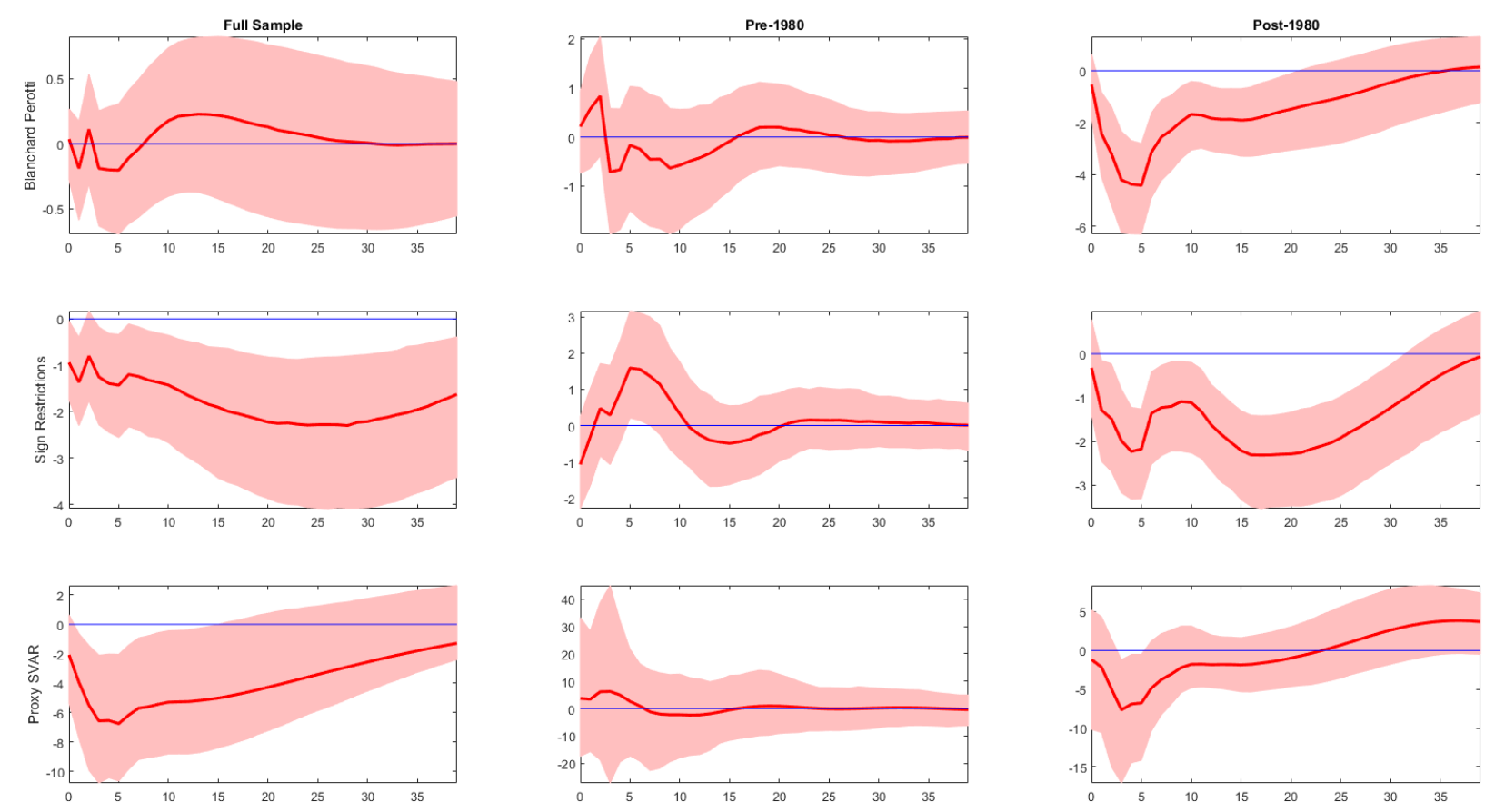

Figure 4: The response of real stock prices to a 1\% increase in government spending. The proxy SVAR uses the spending shock of Ramey (2011) as an instrument. 

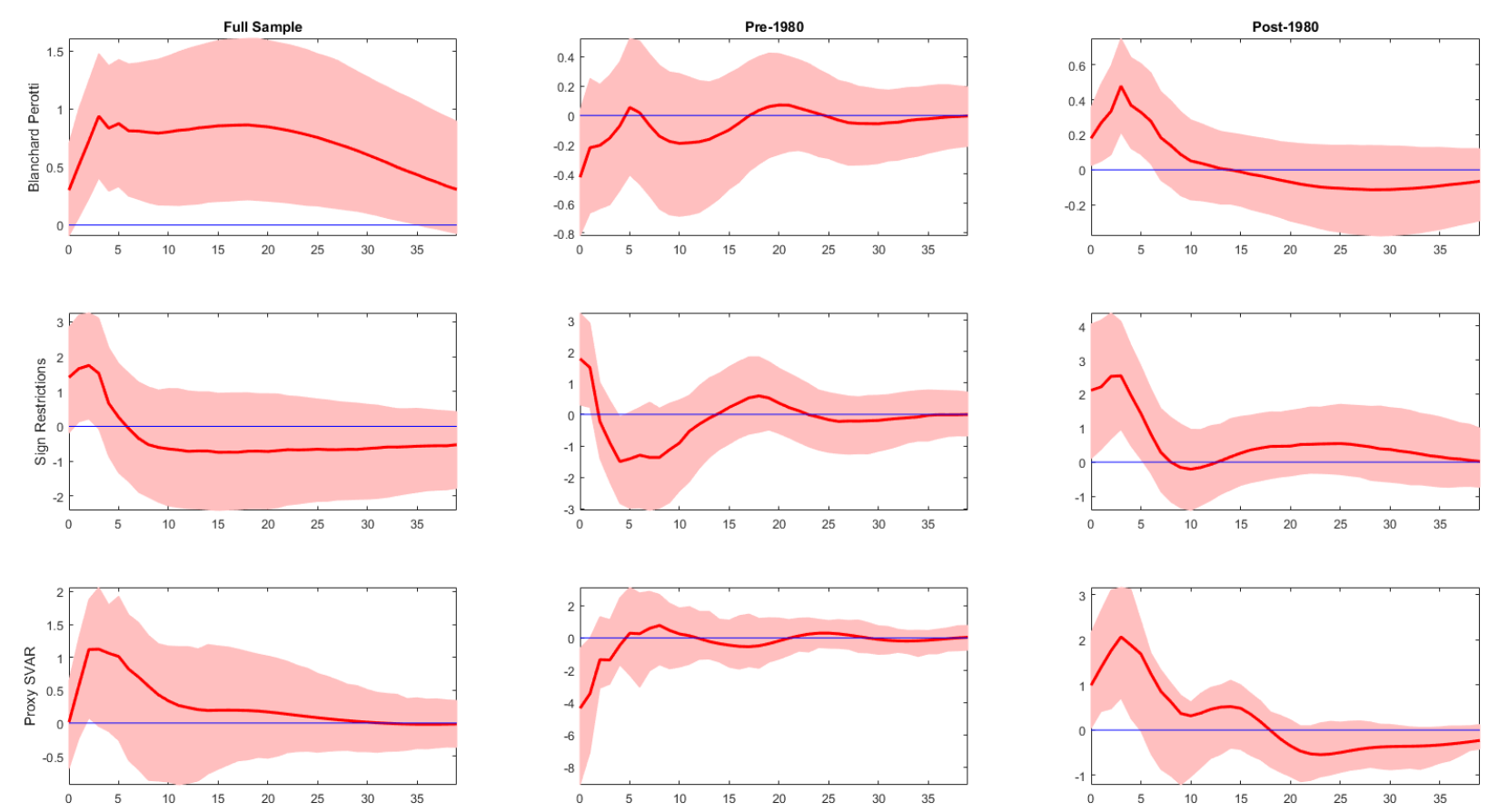

Figure 5: The response of real stock prices to a 1\% increase in government revenue. The proxy SVAR uses the Mertens and Ravn 2012) tax shock as an instrument. 
Policy experiments The impulse responses in figures 1 and 2 report results for 'pure' fiscal shocks where the time-path of the fiscal variables is left unconstrained. In the current application, this implies that the behaviour of taxes (spending) can differ across sub-samples after a spending (tax) shock. To check if the results are sensitive to this feature, we follow Mountford and Uhlig (2009) and consider three policy experiments which constrain the path of the fiscal variables. First, we consider a spending shock that is deficit financed - this shock increases spending by one percent for a year while taxes are constrained to remain at zero. The second policy experiment considers a balanced budget rise in spending - i.e. a spending increase of one percent for one year that is matched by a rise in taxes of 1.2 percent. ${ }^{4}$ Finally we consider a tax cut that is deficit financed taxes fall by one percent for one year while there is no change in spending. As shown in Mountford and Uhlig (2009), these responses can be calculated by choosing the scale of the $G$ and $T$ shocks which delivers the scenarios set out above.

Figure 3 shows the key results from these three experiments. Consider the top three rows which show the impact of a deficit financed increase in spending - as indicated by the shaded area, $G$ is constrained to be at $1 \%$ over the first year of the horizon while $T$ remains at zero. The third row displays the response of stock prices and shows that even when these assumptions are imposed on the two sub-samples, the response of stock prices displays the same shift as indicated by the benchmark - in the post-1980 period stock prices fall while they appear to increase in the earlier sub-sample. The next three rows of the figure show the experiment based on a balanced budget increase in $G$. Again, these assumptions do not alter the conclusions with respect to the change in the response of stock prices across the two sub-samples. Finally, the last three rows show the impact of the deficit financed tax cut. Before 1980, this policy is associated with a mild increase in stock prices. In contrast, stock prices fall in response to this policy change after 1980. These results support those estimated under the pure tax shock scenario shown in figure 2 .

Alternative identification schemes The estimated change in the response of stock prices across the two sub-samples is robust to different methods of identifying innovations to spending and revenue. Figures 4 and 5 present the response of stock prices when the shocks are identified using: (1) the Blanchard and Perotti (2002) and Perotti (2005) scheme, (2) sign restrictions scheme of Mountford and Uhlig (2009) and (3) external instruments in a proxy SVAR. Consider the response to spending shocks shown in Figure 4. The full sample results suggest that the median response of stock prices is negative over, at least, the first year of the horizon, with the most precise results generated by the proxy SVAR and the VAR with sign restrictions. However, as in the benchmark model, the full sample results hide a substantial amount of time-variation. In the pre-1980 period, the evidence for a negative response of stock prices is muted. In contrast after 1980, all the SVARs indicate that stock prices decline in response to this shock.

Figure 5 shows that, one average across the sample, a contractionary tax shock is associated with an increase in stock prices. However, this positive impact is missing (or very short-lived, as in the case of the VAR with sign restrictions) in the pre-1980 period, with the response estimated to be strongly negative in some cases. After 1980, however, there is strong evidence that stock prices rise with a magnitude ranging from $0.5 \%$ to $2 \% 5^{5}$

Further sensitivity analysis We carry out a number of further checks to investigate the robustness of the result that the response of stock prices to fiscal shocks has changed over time.

\footnotetext{
${ }^{4}$ The percent rise in $G$ and $T$ reflect the fact that the share of these variables in GDP is approximately 0.2 and 0.16 , respectively.

${ }^{5}$ The proxy SVAR is estimated using a sample that is finishes in 2006Q4. The fact that the results from this model are close to benchmark suggests that the Great Recession period is not crucial in driving the main results.
} 
Information set First, we consider the possibility of omitted variable bias by trying to account for shocks that may be important for the US economy. In order to preserve degrees of freedom, we add the additional endogenous variables one at a time to the benchmark model which uses the the recursive identification. These variables are ordered after the fiscal indicators.

A large number of recent papers have highlighted the role of uncertainty shocks in driving US macroeconomic and financial variables. To account for this we add the uncertainty index proposed by Jurado et al. (2015) to the benchmark model. The top row of Figure 11 in Appendix B shows that the estimated temporal change in the response of stock prices to fiscal shocks is largely unaffected by this change in model specification. While the pre-1980 response of stock prices to spending and revenue shocks is imprecisely estimated, $S$ falls in response to $G$ shocks and rises on impact in response to $T$ shocks during the post-1980 period.

Following Favero and Giavazzi (2007), we next consider if adding a measure of government debt to the VAR changes the results. The second row of Figure 11 suggests that the estimated change in the response of stock prices pre and post-1980 survives the addition of this variable.

Castelnuovo and Surico (2010) have shown that time-variation in the estimated impact of monetary policy can be affected by the addition of measures of expectations in the VAR model. However when we add the Michigan survey measure of consumer sentiment to the model, the estimated response of stock prices still displays the time-variation detected in the benchmark model (see third row of Figure 11). Next, we add real oil prices to the benchmark model to account for oil shocks in the earlier part of the sample. The fourth row of Figure 11 again shows that the benchmark results are preserved.

The benchmark model does not necessarily account for fiscal news or anticipated fiscal shocks. While we try to tackle this issue by using the Ramey (2011) measure of fiscal news as an instrument in the proxy SVAR, papers such as Rossi and Zubairy (2011) pursue a different approach and add the fiscal news measure as an exogenous variable in a recursive VAR in order to 'filter' the spending shock. The fifth row of Figure 11 shows that when we adopt this approach and add the fiscal news measure as an additional exogenous variable in the benchmark model, the benchmark results survive. This suggests that estimated response of stock prices to proxies for both anticipated and unanticipated spending shocks shows a very similar temporal pattern.

Time-variation The benchmark results are based on splitting the sample in 1979Q4 as in Perotti (2005). The results from this simple approach are supported by a more sophisticated version of the benchmark recursive VAR that allows for time-varying parameters and stochastic volatility àla Primiceri (2005). As the model contains a large number of endogenous variables and lags, estimation is carried out using the algorithm proposed in Koop and Potter (2011). The sixth row of Figure 11 presents the cumulated time-varying response of stock prices at the 2 year horizon to 1 unit increase in spending and revenue, respectively. The figure re-enforces the point that, on average after 1980, the response of $S$ to $G$ and $T$ shocks was substantially different when compared to the pre-1980 period.

Trends Following the literature, we allow for a linear and quadratic trend in the benchmark specification. The final row of Figure 11, instead, presents the cumulated responses from a version of the benchmark model where the variables are first-differenced. As in the benchmark model, stock prices fall in response to spending shocks and rise in response to tax shocks in the post-1980 period. In the pre-1980 period, there is evidence that tax shocks reduce stock prices on impact, while spending shocks have a negligible impact.

To summarise, the impulse response analysis from the numerous VAR models considered above 
suggests two main conclusions:

1. In the pre-1980 period, when fiscal shocks had their largest impact on the real economy, their effect on real stock prices appears to be weak. While there is a suggestion that the median response of $S$ to expansionary fiscal shocks is positive, it is hard to reject the null hypothesis of a zero response in most VAR models we estimate.

2. In the post-1980 period, when the fiscal mutiplier declined, the impact of fiscal shocks on stock prices increased in magnitude and appeared to change sign. In fact, there is strong evidence that after 1980 expansionary fiscal shocks lead to a reduction in stock prices. 

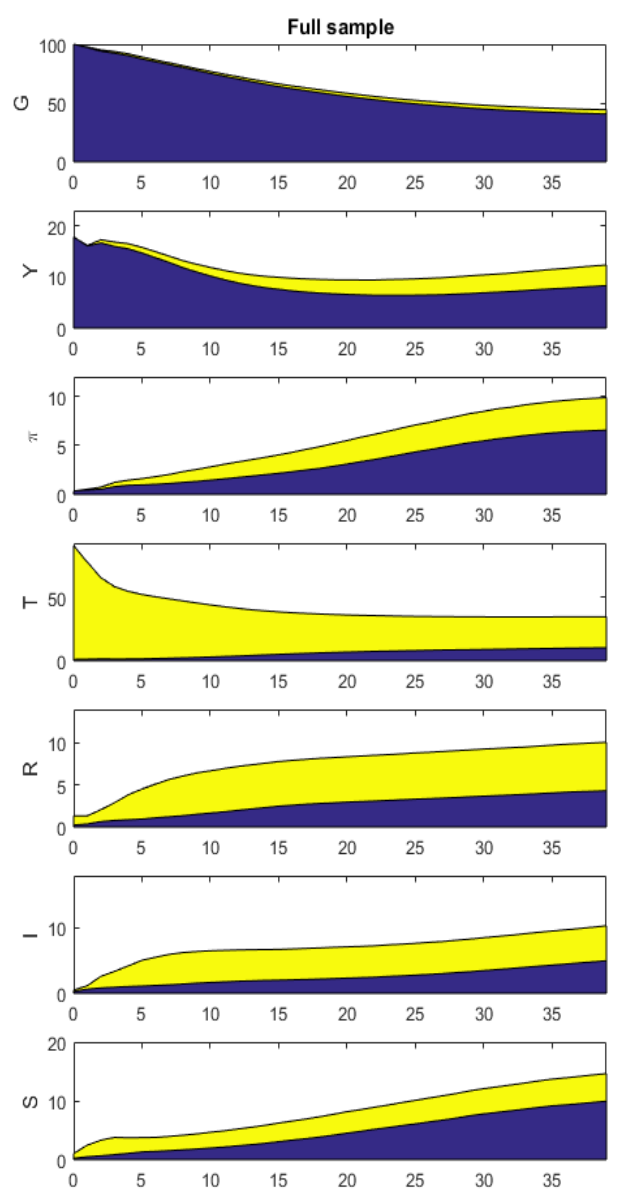

Figure 6: The percentage contribution of spending and revenue shocks to the forecast error variance
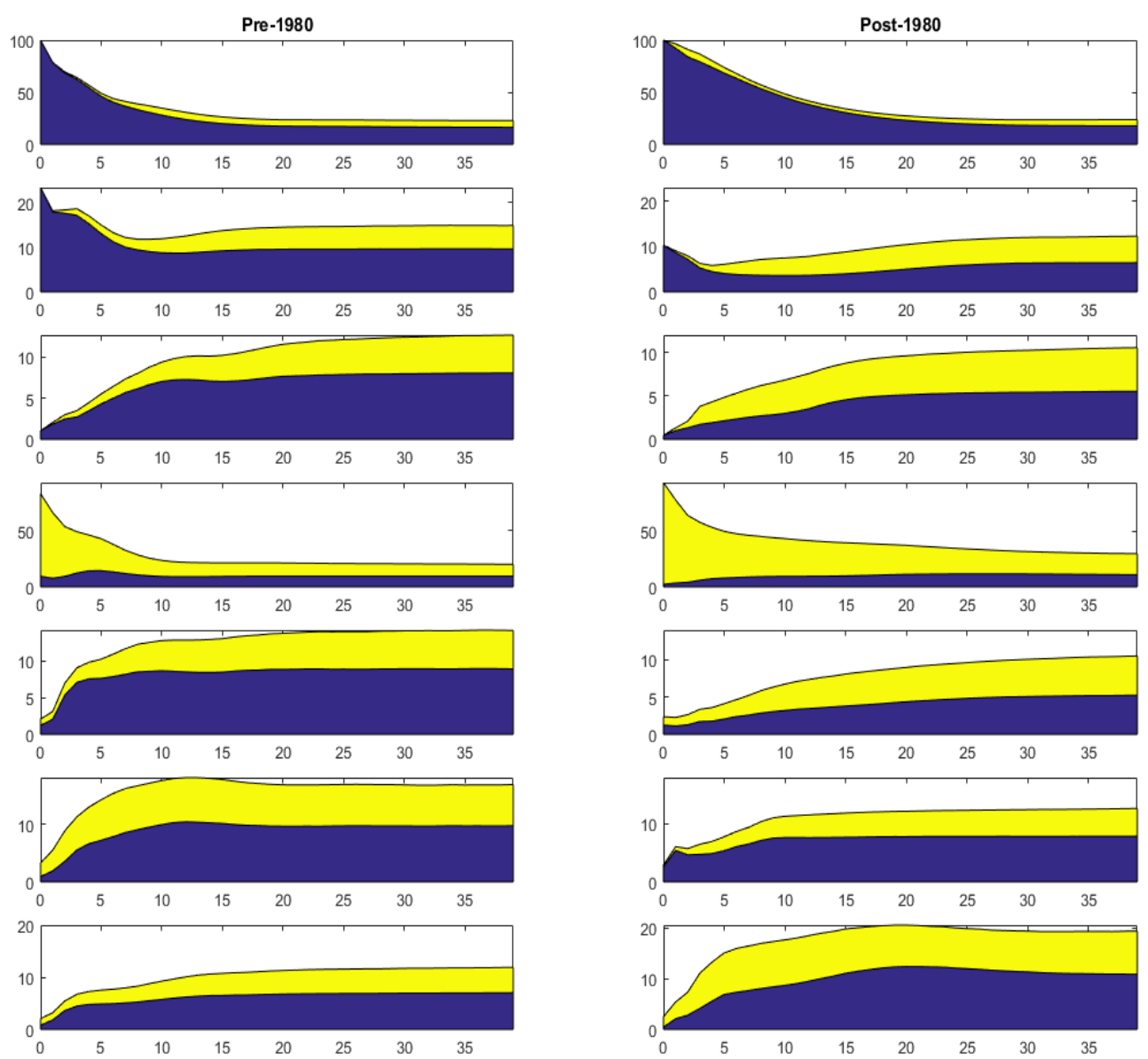

\begin{tabular}{ccccc}
10 & 15 & 20 & 25 & 30 \\
\hline & G shocks & & \\
\hline & T shocks
\end{tabular}

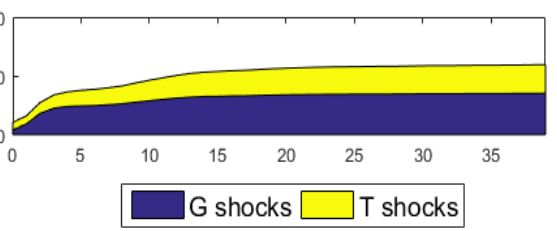




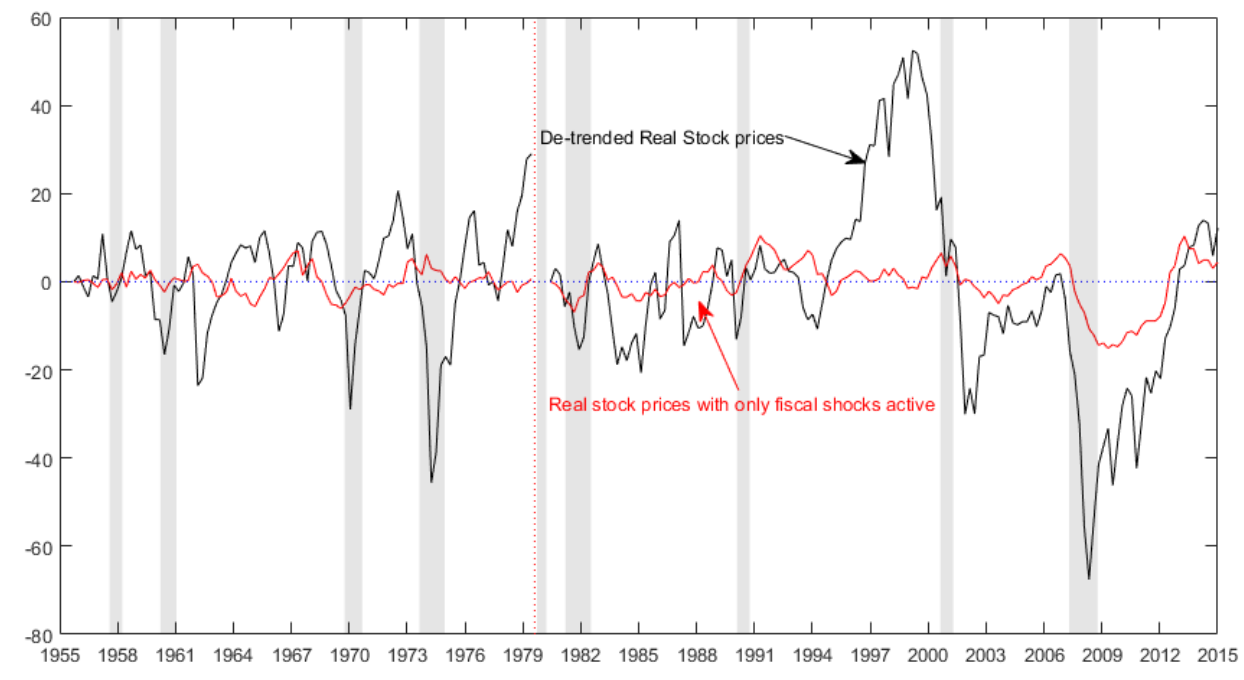

Figure 7: Real stock prices relative to VAR implied trend. The black line is actual data while the red line is the counter-factual estimate under the scenario that only $\mathrm{G}$ and $\mathrm{T}$ shocks are active. The grey-shaded areas represent NBER recession dates.

\subsubsection{The contribution of fiscal shocks to stock prices}

Figure 6 shows the estimated contribution of the fiscal shocks to the forecast error variance (FEV) of the endogenous variables using the benchmark VAR model. At the one year horizon, fiscal shocks contribute about $17 \%$ to the FEV of GDP. However, as in the case of impulse responses the results change over time. In particular, the contribution of fiscal shocks to GDP is substantially smaller in the post-1980 period. The same decline can be see in the contribution of these shocks to inflation and the interest rates. However, in contrast, the contribution of these shocks to stock price FEV has increased after 1980. In the pre-1980 period, this contribution was about $7 \%$ at the one-year horizon reaching a maximum of $12 \%$ in the long-run. After 1980 the fiscal shocks contributed $11 \%$ at the one-year horizon with the contribution rising close to $20 \%$ in the long-run.

A similar picture emerges when the historical decomposition of stock prices is considered. Figure 7 presents stock prices relative to trend and the counter-factual estimate of $S$ assuming only spending and revenue shocks are active. The figure presents this decomposition using the benchmark VAR estimated in the two sub-samples with the vertical line indicating the sample split. First, it is clearly evident that the historical contribution of fiscal shocks is smaller in the pre-1980 period. The period following the 1981 Reagan tax cut coincides with a negative contribution of fiscal shocks with these effects reversed with the tax increases in 1982. Similarly, the tax increases of the early 1990s under the the Omnibus Budget reconciliation acts are associated with a positive contribution to stock prices. Fiscal shocks make a modest negative contribution during the Bush tax cuts in early 2000s. It is interesting to note that the fiscal expansion associated with the stimulus acts 2008-2010 coincided with a large negative contribution of fiscal shocks to $S$. These results re-enforce the conclusions reached above via impulse response analysis - after 1980 expansionary fiscal shocks are increasingly associated with a reduction in stock prices. 


\section{Explaining the change. A DSGE model}

Why is the response of stock prices to fiscal shocks different after 1980? We attempt to answer this question using an estimated DSGE model - As in Traum and Yang (2011), we augment the model developed by Christiano et al. (2005) and Smets and Wouters (2007) with a simple non-productive government sector. In this section we present a description of the key features of this model. A complete description of each sector is provided in the technical appendix to the paper.

\subsection{Key features of the model}

The model features monopolistically competitive households who consume, supply labour and capital services. As in Erceg et al. (2000), the household supplies a differentiated labour service to the production section. They set their nominal wage and supply any amount of labour demanded by the firms at that wage rate. In each period, a fraction of households receive a random signal and they are allowed to reset wages optimally while all other households can only partially index their wages to past inflation. The firm sector in the model consists of a continuum of intermediate producers that employ labour and capital services to produce the intermediate good for sale to the final producer. Intermediate producers operate in two stages: First, they take wage and rental rate of capital as given and decide about labour and capital demand by maximising their profits. Second, they decide about what price to charge with a fraction of firms allowed to reset their price each period. The government sector consists of a fiscal authority and a monetary authority. Fiscal authorities finance government consumption and transfers by raising revenues from taxation and issuing new debt. The budget constraint of the fiscal authority is given by:

$$
\frac{\tilde{B}_{t}}{R_{t}^{G}}+\tau_{t}\left(R_{t}^{K} v_{t} \tilde{K}_{t-1}+\tilde{W}_{t} L_{t}\right)=\frac{\tilde{B}_{t-1}}{\Pi_{t}}+\tilde{G}_{t}+\widetilde{T R}
$$

Here, $\tilde{B}_{t}$ denotes government debt, $\tau_{t}$ is the tax rate, $R_{t}^{G}$ is the effective interest rate faced by households, $R_{t}^{K}$ is the rental rate of capital $\left(v_{t} \tilde{K}_{t-1}\right), \tilde{W}_{t}$ is wage, $L_{t}$ denotes hours worked, $\Pi_{t}$ is inflation, while $\tilde{G}_{t}$ and $\widetilde{T R}$ denote government consumption and transfers, respectively $\left[{ }^{6}\right.$ Debt and tax decisions are based on the following simple rule:

$$
\frac{\tau_{t}}{\tau}=\left(\frac{\tau_{t-1}}{\tau}\right)^{\rho_{\tau}}\left(\frac{\tilde{B}_{t-1}}{\tilde{Y}_{t-1}} / \frac{B}{Y}\right)^{\left(1-\rho_{\tau}\right) \zeta_{\tau}}
$$

where $\tilde{Y}_{t}$ is output. Government consumption evolves as a stationary exogenous process.

As discussed in Leeper (1991), a fiscal authority is characterised as 'passive' when it sets taxes in a way that restores debt back to its steady state value. In the rule given by equation 2 , this is achieved by setting $\zeta_{\tau}$ greater than $\frac{\Pi \Gamma}{\beta}-1$ where $\beta$ is the households' time discount factor and $\Gamma$ is steady state productivity. When authorities' tax reaction function does not satisfy the latter condition $\left(\zeta_{\tau}<\frac{\Pi \Gamma}{\beta}-1\right)$, then they actively destabilise the debt.

The monetary authority sets the policy interest rate $R_{t}$ via the rule:

$$
\frac{R_{t}}{R}=\left(\frac{R_{t-1}}{R}\right)^{\rho_{R}}\left(\frac{\Pi_{t}}{\Pi}\right)^{\left(1-\rho_{R}\right) \gamma_{\pi}}\left(\frac{Y_{t}}{Y}\right)^{\left(1-\rho_{R}\right) \gamma_{y}} \exp ^{\sigma_{R} \varepsilon_{R, t}}
$$

\footnotetext{
${ }^{6}$ Non stationary variables are denoted by the superscript $\sim$. Variables without a time subscript are steady state values.
} 
Monetary policy is considered as passive if the reaction of the policy rate to changes in the inflation is not strong enough to stabilise inflation expectations $\left(\gamma_{\pi}<1\right)$. When $\gamma_{\pi}>1$ monetary policy is viewed as active as it guarantees that long run inflation expectations coincide with the inflation target.

Following Swanson (2015a), an equity security in the model is defined as a levered claim on the aggregate consumption. Every period, the equity security pays a dividend equal to $c_{t}^{\vartheta}$ where $\vartheta$ captures the degree of leverage. In this case the price of the equity is defined as

$$
q_{e, t}=E_{t} m_{t+1}\left(c_{t+1}^{\vartheta}+q_{e, t+1}\right)
$$

where $m_{t}$ is the stochastic discount factor.

\subsubsection{Estimation}

We estimate the parameters of the model using Bayesian techniques. As in the case of the SVARs, the estimation is carried out on two sub-samples. The first sub-sample ranges from 1955 Q1 to 1979 Q4. The second sub-sample runs from 1980 Q1 to 2007 Q4. As the model does not directly account for the ZLB and unconventional policies, we restrict the second sub-sample to 2007. While adding these features to the model is an interesting task in general, it is not central to the aim of explaining the change in the response of stock prices to fiscal shocks in 1980.

The sample is split in 1980 to match the SVAR analysis. However, there are many studies in the literature (Traum and Yang (2011), Leeper et al. (2015), Kliem et al. (2016) among others) that adopt a very similar sub-sample analysis to investigate simultaneous changes in the preferences of both fiscal and monetary authorities. Furthermore, the studies of Bianchi and Ilut (2014) and Bianchi and Melosi (2017) seem to justify empirically a very similar split of the data. Their methodology allows the policy parameters to evolve stochastically from one regime to another. Although the process that 'drives' these switches is unobserved, it can be inferred from the data by using filtering techniques. This analysis reveals that the time period of changes in the policy parameters seems to coincide with the split of the sample adopted in the literature.

As described in detail in the technical appendix, we follow Del Negro and Schorfheide (2008) (among others) and use priors that are formed 'endogenously'. In other words, the priors for the parameters (which are based on common choices in the literature) are conditioned on beliefs about data moments of interest. In our application these moments are impulse responses to government spending shocks and the beliefs are centered on the estimates obtained from the benchmark SVAR model. As shown above, the SVAR results are robust across numerous permutations of the empirical model and the approach of Del Negro and Schorfheide (2008) allows us to incorporate this information into the DSGE estimation thus ameliorating the effect of the short data span in the two sub-samples. The technical appendix shows that the key results are robust to the degrees of tightness of the prior distribution.

\subsection{Results}

The posterior estimates of the model parameters reveal a very interesting pattern of policy changes. The $90 \%$ highest posterior density interval (HPDI) for the parameter governing monetary policy activism, $\gamma_{\pi}$, is estimated to be $(0.37,0.6)$ in the first sub-sample and monetary policy is passive. After 1980, there is strong evidence in favour of more active policy with the HPDI rising to $(1.5,1.9)$. In contrast, we estimate that fiscal policy is passive in the second sub-sample: The $90 \%$ HPDI for $\zeta_{\tau}$ is estimated to be $(0.03,0.08)$ while $\frac{\Pi \Gamma}{\beta}-1=0.02$. Evidence for fiscal policy activism is stronger 
before 1980 with the HPDI of $\zeta_{\tau}$ estimated to be $(0.003,0.02)$ and $\frac{\Pi \Gamma}{\beta}-1=0.02$. The posterior estimates of the remaining parameters fall well in the range reported in the literature (Christiano et al. (2005), Smets and Wouters (2007), Justiniano et al. (2010), Del Negro et al. (2015) among others) and are described in the technical appendix.

\subsubsection{Impulse responses and variance decomposition}



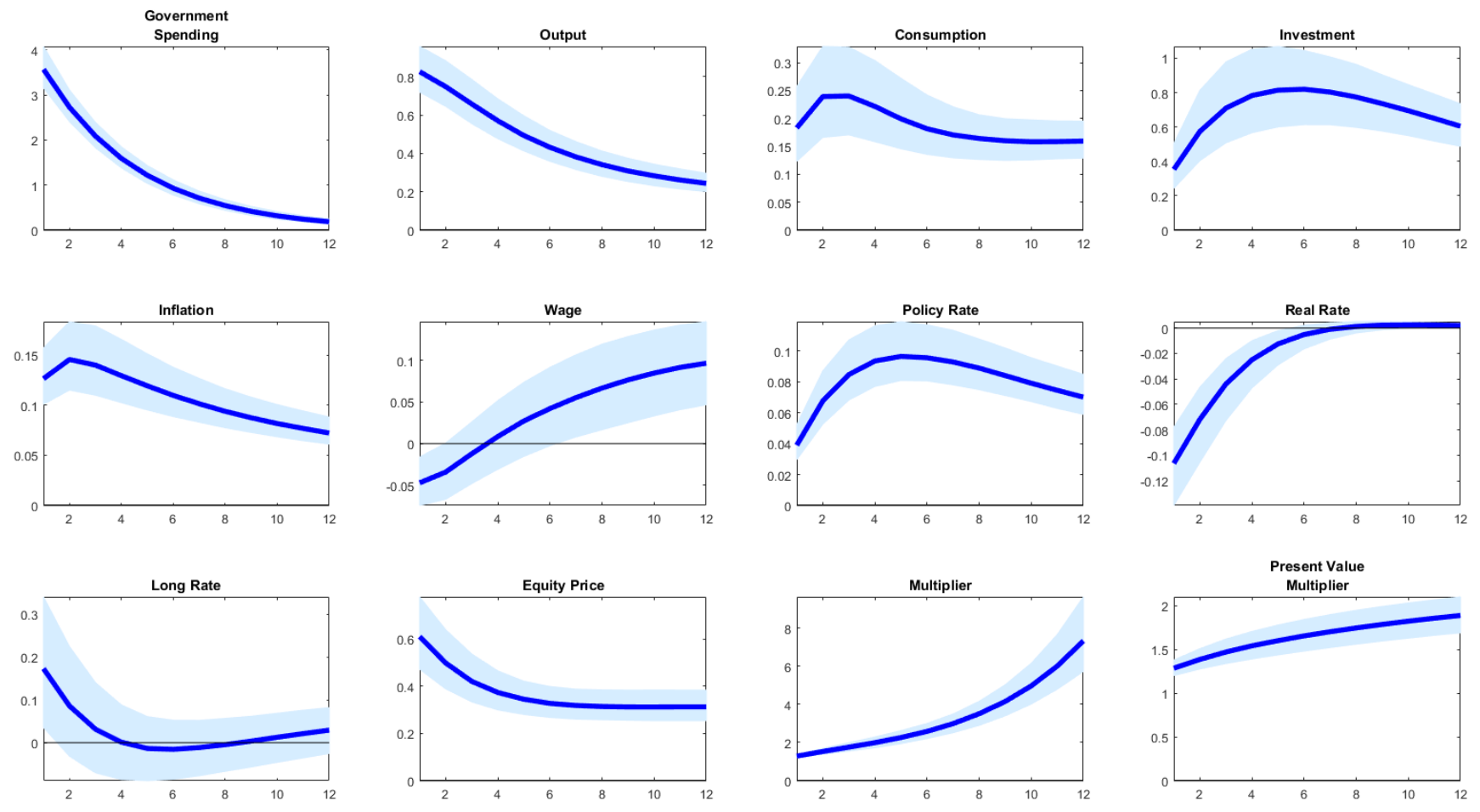

Figure 8: Pre-1980 estimates of the response to a government spending shock. The solid line represents the pointwise median impulse response function, and the shaded area is the corresponding 5th and 95th percentiles of the posterior distribution. The horizontal axes are in quarters, the vertical axes are in percentage points. The multiplier is defined as $M_{i}=\frac{Y}{G} \hat{G}_{i}$, and the present value multiplier is defined as $P V M_{i}=\frac{Y}{G} \frac{\sum_{j=0}^{i}\left(\prod_{k=0}^{i}\left(1+\hat{R}_{k}\right)^{-1}\right) \hat{G}_{j}}{\sum_{j=0}^{i}\left(\prod_{k=0}^{i}\left(1+\hat{R}_{k}\right)^{-1}\right) \hat{Y}_{j}}$. The superscript ^ denotes deviations from steady state. 

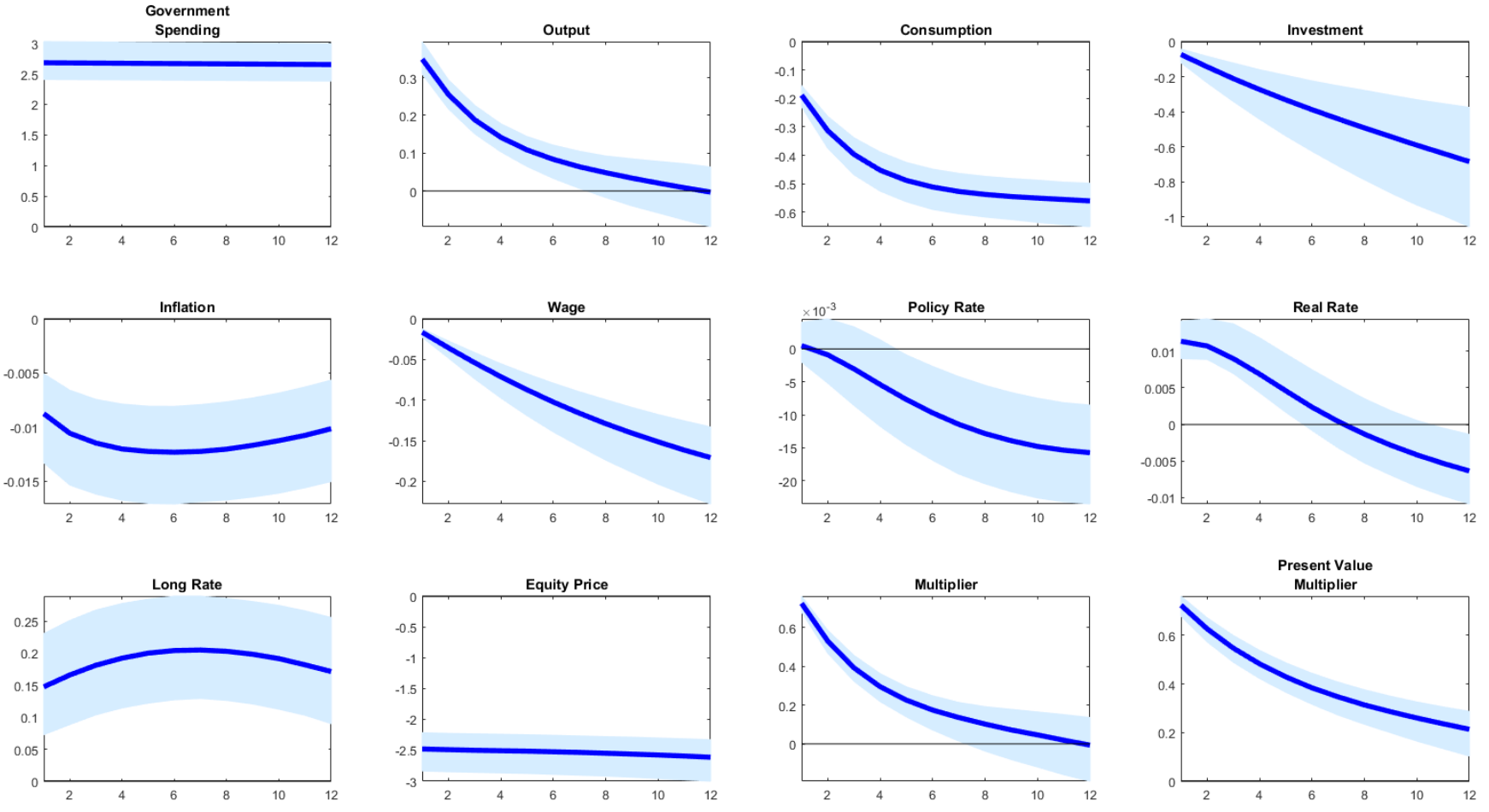

Figure 9: Post-1980 estimates of the response to a government spending shock. See notes to figure 8. 

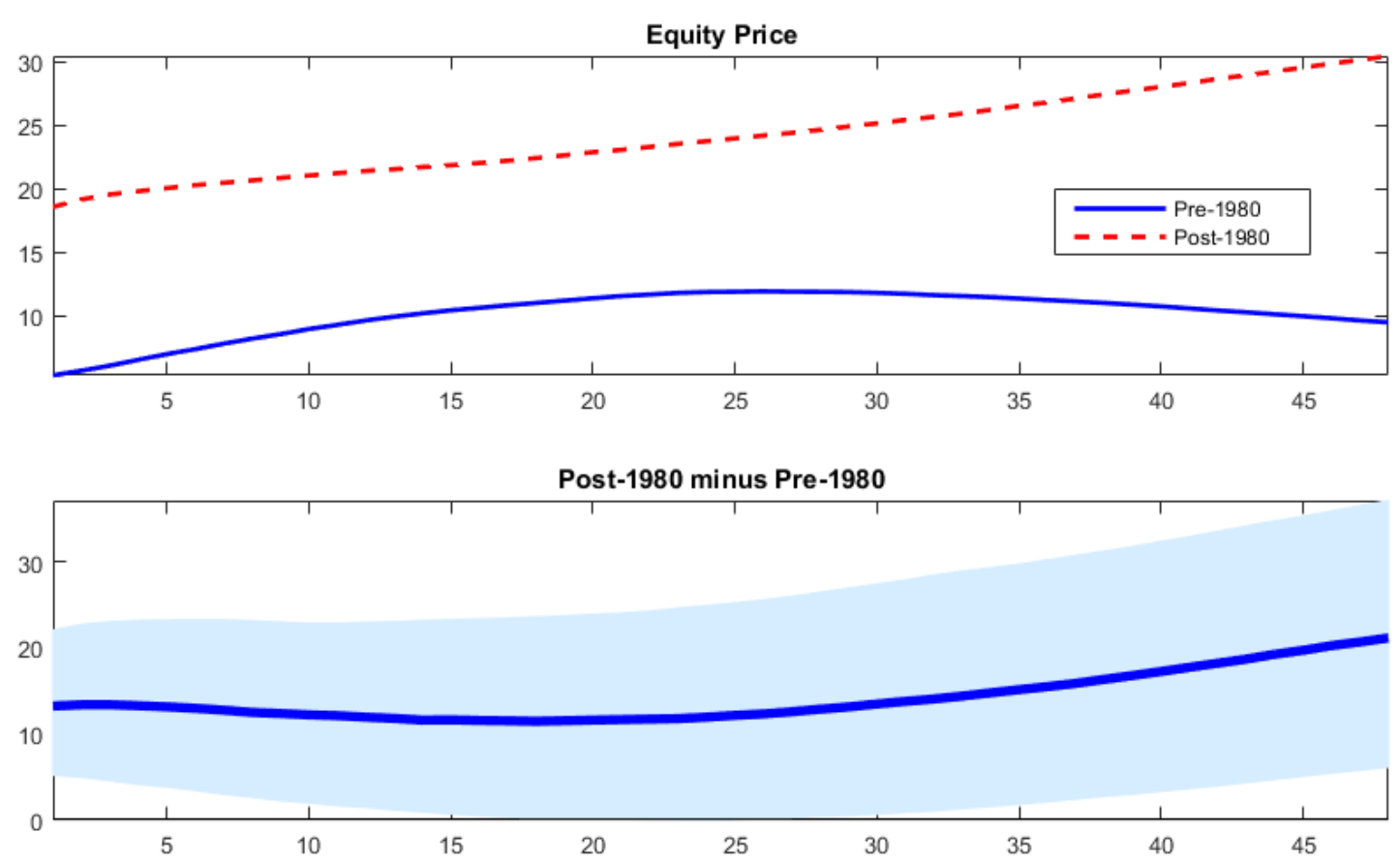

Figure 10: Contribution of the government spending shock to the FEV of equity prices. The bottom panel shows the posterior distribution of the difference in the post and pre-1980 contribution. 
Figures 8 and 9 present the estimated response to a government spending shock in the two subsamples. Consider the pre-1980 results. A passive monetary authority allows inflation expectations to rise after a positive government spending shock and the real real interest rate declines. A lower real interest rate implies higher consumption and investment demand with an output multiplier that is greater than 1 at the two year horizon. Private demand is boosted further by the fact that fiscal authorities react to government debt only weakly. As discussed in Leeper et al. (2015), the latter effect is small as the existence of steady state taxes ensures that the tax revenue increases along with the expansion of the real economy and this reduces the wealth effects induced by active fiscal authorities. Given high aggregate consumption and low real rates after the shock, equity prices rise.

The post-1980 estimates are a mirror image of the pre-1980 results. In this regime, both authorities set policy in a manner that it is consistent with their objectives. However, as these policies are uncoordinated, any stimulatory effect from a government spending shock is cancelled out by the higher real rates and higher taxes. As a result, the output multiplier is substantially smaller in this regime. Note that as the real interest rate rises and consumption falls, the expansionary spending shock causes the equity price to decline by a substantial amount.

Figure 10 shows that in symmetry with the SVAR results, the DSGE estimates suggest that the contribution of fiscal shocks to equity prices has increased after 1980, rising by about $10 \%$, Furthermore, the second row of the figure shows that this change is systematic and the null of stability can be rejected.

\subsubsection{Discussion}

In summary, the posterior estimates of the DSGE model provide one compelling explanation for the SVAR results. We find that the fall in equity prices in response to expansionary fiscal shocks estimated after 1980 may be a manifestation of the activism of monetary authorities over a period of passive fiscal policy. Before 1980, monetary policy is estimated to be passive while the posterior estimates of the tax rule point to higher degree of fiscal activism. As a result, expansionary fiscal shocks over this period were associated with modest increases in equity prices.

These results are of relevance to the recent discussion about the switch from the passive monetary \& active fiscal policy to active monetary \& passive fiscal policy regime in papers such as Bianchi and Ilut (2014) and Bianchi and Melosi (2017) . Our findings are consistent with the results of Bianchi and Ilut (2014) and Bianchi and Melosi (2017) even though we apply a very different methodology. Futhermore, our results contribute to the literature regarding the Great moderation and policy switches (Lubik and Schorfheide (2004), Sims and Zha (2006), Cogley and Sargent (2005), Cogley et al. (2010)). The DSGE analysis provides important results on the size of the fiscal multiplier. We show that an estimated Smets and Wouters (2007) type model can deliver a multiplier greater than one without modelling features such long-run debt, rule of thumb consumers and complementarity between government and private consumption (Bianchi and Ilut (2014), Leeper et al. (2015), Bianchi and Melosi (2017)). Our analysis suggest that a fiscal expansion does not need to crowd out private demand if the real interest rate falls. This has direct implications for central banks and it suggests that successful fiscal expansions require a high degree of coordination between the two authorities. Finally, our results have implications for the literature that uses asset prices to identify the effects of policy actions (Wright (2012), Joyce et al. (2011), Gilchrist and Zakrajsek (2013)). Our study suggests that asset prices can increase after a fiscal expansion that is not offset by monetary policy and this prediction can be used to infer the effectiveness of the policy announcement in real time. 


\section{Conclusions}

In this paper we use a battery of SVAR models to show that the response of US stock prices to an expansionary fiscal shock has changed after 1980. Before this date, an expansionary fiscal shock was associated with modest increases in stock prices. Post-1980, the same shock is associated with large declines in stock prices with spending and revenue shocks making a larger contribution to the forecast error variance.

We then use an estimated DSGE model to show this shift in the response can be explained by a change in policy activism. The pre-1980 period is found to be characterised by active fiscal policy and passive monetary policy. This policy mix allowed the real interest rate to fall after a fiscal expansion boosting equity prices. After 1980 monetary policy is estimated to be active while the fiscal authority is found to be passive. As a consequence positive fiscal shocks result in real interest rate increases causing consumption and equity prices to decline.

These results have important policy implications. In particular, the analysis suggests that the large increases in stock prices witnessed after the presidential election of 2016 might be reversed if the new administration implements its plans for a fiscal expansion. This, again, highlights the importance of the interaction between fiscal and monetary policy.

In future work it would be interesting to explore if the temporal shift documented in this paper also apply to other developed countries such as the United Kingdom. It may also be useful to investigate if fiscal shocks have economically significant effects on prices of other assets such as homes and whether the estimated impact is stable through time.

\section{References}

Afonso, Ant Âşnio and Ricardo M. Sousa, 2011, What are the effects of fiscal policy on asset markets?, Economic Modelling 28(4), 1871 - 1890.

Ardagna, Silvia, 2009, Financial marketsâĂŹ behavior around episodes of large changes in the fiscal stance, European Economic Review 53(1), 37 - 55.

Bianchi, Francesco and Cosmin Ilut, 2014, Monetary/Fiscal Policy Mix and Agents' Beliefs, NBER Working Papers 20194, National Bureau of Economic Research, Inc.

Bianchi, Francesco and Leonardo Melosi, 2017, Escaping the Great Recession, American Economic Review forthcoming.

Bilbiie, Florin O., Andre Meier and Gernot J. Muller, 2008, What Accounts for the Changes in U.S. Fiscal Policy Transmission?, Journal of Money, Credit and Banking 40(7), 1439-1470.

Blanchard, Olivier J., 1981, Output, the Stock Market, and Interest Rates, The American Economic Review 71(1), 132-143.

Blanchard, Olivier and Roberto Perotti, 2002, An Empirical Characterization of the Dynamic Effects of Changes in Government Spending and Taxes on Output, The Quarterly Journal of Economics 117(4), 1329-1368.

Caldara, Dario and Christophe Kamps, 2008, What are the effects of fiscal policy shocks? A VAR-based comparative analysis, Working Paper Series 0877, European Central Bank. 
Castelnuovo, Efrem and Paolo Surico, 2010, Monetary Policy, Inflation Expectations and The Price Puzzle*, The Economic Journal 120(549), 1262-1283.

Chatziantoniou, Ioannis, David Duffy and George Filis, 2013, Stock market response to monetary and fiscal policy shocks: Multi-country evidence, Economic Modelling 30, 754 - 769.

Christiano, Lawrence, Martin Eichenbaum and Charles Evans, 2005, Nominal Rigidities and the Dynamic Effects of a shock to Monetary Policy, Journal of Political Economy 113, 1-45.

Cogley, Timothy, Giorgio E. Primiceri and Thomas J. Sargent, 2010, Inflation-Gap Persistence in the US, American Economic Journal: Macroeconomics 2(1), 43-69.

Cogley, Timothy and Thomas J. Sargent, 2005, Drift and Volatilities: Monetary Policies and Outcomes in the Post WWII U.S, Review of Economic Dynamics 8(2), 262-302.

Del Negro, Marco and Frank Schorfheide, 2008, Forming priors for DSGE models (and how it affects the assessment of nominal rigidities), Journal of Monetary Economics 55(7), 1191-1208.

Del Negro, Marco, Marc P. Giannoni and Frank Schorfheide, 2015, Inflation in the Great Recession and New Keynesian Models, American Economic Journal: Macroeconomics 7(1), 168-96.

Erceg, Christopher J., Dale W. Henderson and Andrew T. Levin, 2000, Optimal monetary policy with staggered wage and price contracts, Journal of Monetary Economics 46(2), 281-313.

Favero, Carlo and Francesco Giavazzi, 2007, Debt and the Effects of Fiscal Policy, Working Paper 12822, National Bureau of Economic Research.

Galí, Jordi and Luca Gambetti, 2015, The Effects of Monetary Policy on Stock Market Bubbles: Some Evidence, American Economic Journal: Macroeconomics 7(1), 233-257.

Gambacorta, Leonardo, Boris Hofmann and Gert Peersman, 2014, The Effectiveness of Unconventional Monetary Policy at the Zero Lower Bound: A Cross-Country Analysis, Journal of Money, Credit and Banking 46(4), 615-642.

Gilchrist, Simon and Egon Zakrajsek, 2013, The Impact of the Federal Reserve's Large?Scale Asset Purchase Programs on Corporate Credit Risk, Journal of Money, Credit and Banking 45(s2), 2957.

Joyce, Michael A. S., Ana Lasaosa, Ibrahim Stevens and Matthew Tong, 2011, The Financial Market Impact of Quantitative Easing in the United Kingdom, International Journal of Central Banking 7(3), 113-161.

Jurado, Kyle, Sydney C. Ludvigson and Serena Ng, 2015, Measuring Uncertainty, American Economic Review 105(3), 1177-1216.

Justiniano, Alejandro, Giorgio Primiceri and Andrea Tambalotti, 2010, Investment shocks and business cycles, Journal of Monetary Economics 57(2), 132-45.

Kliem, Martin, Alexander Kriwoluzky and Samad Sarferaz, 2016, Monetary?fiscal policy interaction and fiscal inflation: A tale of three countries, European Economic Review 88(C), 158-184.

Koop, Gary and Simon M. Potter, 2011, Time varying VARs with inequality restrictions, Journal of Economic Dynamics and Control 35(7), 1126-1138. 
Leeper, Eric M., 1991, Equilibria under 'active' and 'passive' monetary and fiscal policies, Journal of Monetary Economics 27(1), 129-147.

Leeper, Eric M., Nora Traum and Todd B. Walker, 2015, Clearing Up the Fiscal Multiplier Morass: Prior and Posterior Analysis, NBER Working Papers 21433, National Bureau of Economic Research, Inc.

Lubik, Thomas A. and Frank Schorfheide, 2004, Testing for Indeterminacy: An Application to U.S. Monetary Policy, American Economic Review 94(1), 190-217.

Mertens, Karel and Morten O. Ravn, 2012, Empirical Evidence on the Aggregate Effects of Anticipated and Unanticipated US Tax Policy Shocks, American Economic Journal: Economic Policy $4(2), 145-81$.

Mertens, Karel and Morten O. Ravn, 2013, The Dynamic Effects of Personal and Corporate Income Tax Changes in the United States, American Economic Review 103(4), 1212-47.

Mertens, Karel and Morten O. Ravn, 2014, A reconciliation of SVAR and narrative estimates of tax multipliers, Journal of Monetary Economics 68(S), S1-S19.

Mountford, Andrew and Harald Uhlig, 2009, What are the effects of fiscal policy shocks?, Journal of Applied Econometrics 24(6), 960-992.

Mumtaz, Haroon and Angeliki Theophilopoulou, 2016, The Impact of Monetary Policy on Inequality in the UK. An Empirical Analysis, Working Papers 783, Queen Mary University of London, School of Economics and Finance.

Perotti, Roberto, 2005, Estimating the effects of fiscal policy in OECD countries, Proceedings .

Primiceri, G, 2005, Time varying structural vector autoregressions and monetary policy, The Review of Economic Studies 72(3), 821-52.

Ramey, Valerie A., 2011, Identifying Government Spending Shocks: It's all in the Timing*, The Quarterly Journal of Economics .

Romer, Christina D. and David H. Romer, 2010, The Macroeconomic Effects of Tax Changes: Estimates Based on a New Measure of Fiscal Shocks, American Economic Review 100(3), 763801.

Rossi, Barbara and Sarah Zubairy, 2011, What Is the Importance of Monetary and Fiscal Shocks in Explaining U.S. Macroeconomic Fluctuations?, Journal of Money, Credit and Banking 43(6), 1247-1270.

Sims, Christopher A. and Tao Zha, 2006, Were There Regime Switches in U.S. Monetary Policy?, American Economic Review 96(1), 54-81.

Smets, Frank and Rafael Wouters, 2007, Shocks and Frictions in US Business Cycles: a Bayesian DSGE Approach, American Economic Review 97, 586-606.

Stock, James H. and Mark W. Watson, 2008, WhatâĂŹs New in Econometrics- Time Series, Lecture 7, National Bureau of Economic Research, Inc.

Swanson, Eric, 2015a, A Macroeconomic Model of Equities and Real, Nominal, and Defaultable Debt, Mimeo, University of California Irvine. 
Swanson, Eric T., 2015b, Measuring the Effects of Unconventional Monetary Policy on Asset Prices, Working Paper 21816, National Bureau of Economic Research.

Traum, Nora and Shu-Chun S. Yang, 2011, Monetary and fiscal policy interactions in the post-war U.S, European Economic Review 55(1), 140-164.

Wright, Jonathan H., 2012, What does Monetary Policy do to Long?term Interest Rates at the Zero Lower Bound?, Economic Journal 122(564), F447-F466.

Wu, Jing Cynthia and Fan Dora Xia, 2014, Measuring the Macroeconomic Impact of Monetary Policy at the Zero Lower Bound, NBER Working Papers 20117, National Bureau of Economic Research, Inc.

\section{A Appendix A: Data sources}

BEA refers to Bureau of Economic Analysis (http://www.bea.gov/), FRED is Federal Reserve Economic data (http://research.stlouisfed.org/fred2/) and GFD refers to Global Financial Data.

\section{Fiscal data}

- Government spending: Government consumption expenditures and gross investment (BEA Table 1.15 Line 22) divided by population and deflated by the GDP deflator.

- Net Taxes: Current Receipts (BEA Table 3.1 Line 1) minus current transfer payments (BEA Table 3.1 Line 22) and interest payments (BEA Table 3.1 Line 27) divided by population and deflated by the GDP

- Government Debt: Federal Debt Held by the Public (FRED series id FYGFDPUN) divided by nominal GDP.

- Tax shock calculated by Mertens and Ravn (2012).

Downloaded from https://www.aeaweb.org/articles?id=10.1257/pol.4.2.145.

- News in government defence spending calculated by Ramey (2011).

Downloaded from http://econweb.ucsd.edu/ ${ }^{\sim}$ vramey/research.html\#data.

\section{Macroeconomic/Financial data}

- Real GDP per capita: Real GDP (FRED series id GDPC96) divided by population.

- CPI (FRED series id CPIAUCSL). We calculate inflation as the annual growth in CPI.

- 3 month Treasury Bill rate (FRED series id TB3MS). From 2009Q1 to 2015Q4, we use the shadow rate calculated by $\mathrm{Wu}$ and $\mathrm{Xia}$ (2014). This is obtained from the Federal Reserve Bank of Atlanta.

- Real Stock Prices

- 10-year government bond yield (GFD code IGUSA10D).

- Consumer Confidence index: University of Michigan Consumer sentiment (FRED id UMCSENT and UMCSENT1). 
- Uncertainty index calculated by Jurado et al. (2015).

Dowloaded from https://www.sydneyludvigson.com/data-and-appendixes/.

- Population ( FRED series id POP)

- GDP deflator (FRED series id GDPDEF)

\section{B Appendix B: Robustness}



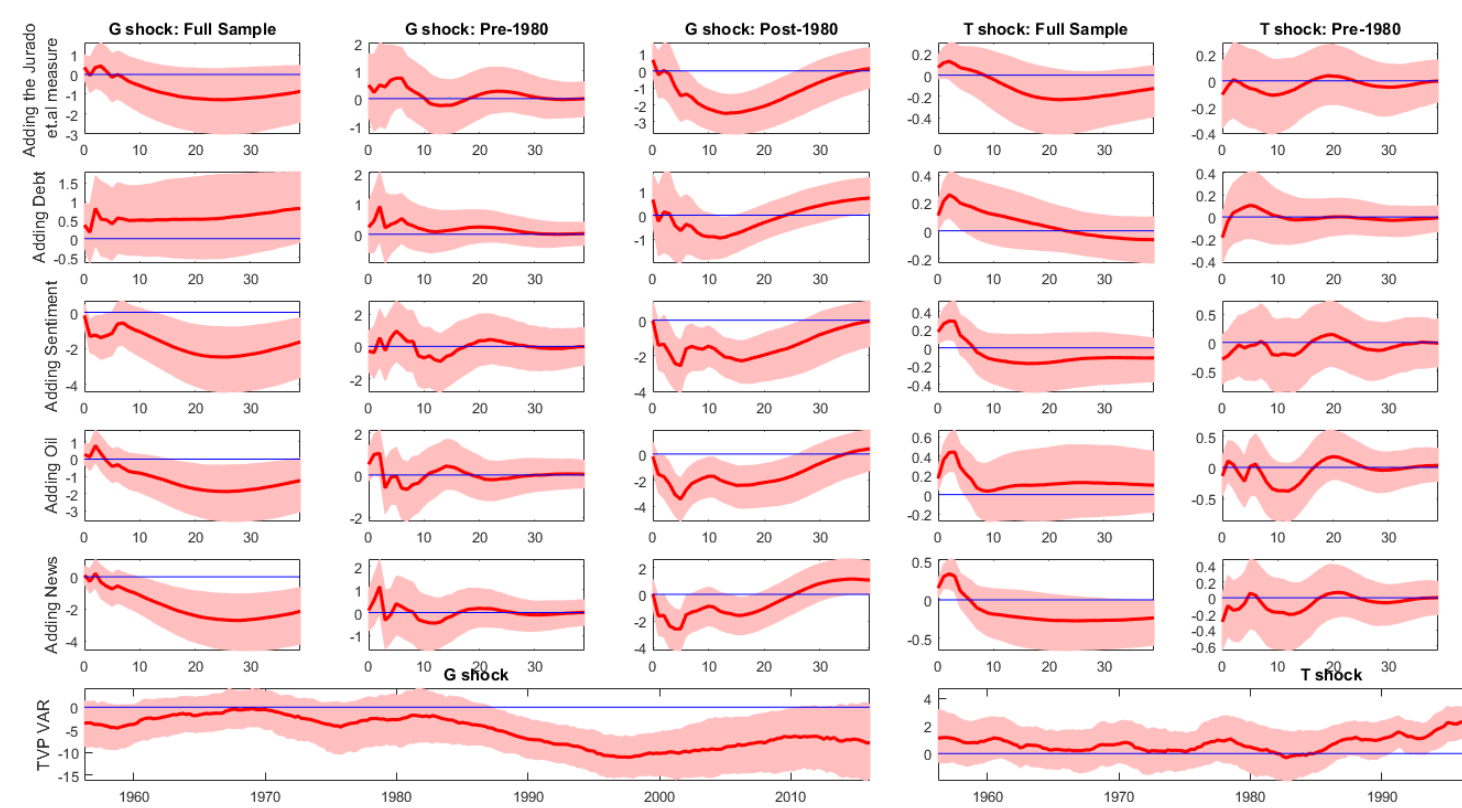

$\begin{array}{llll}0.5 & 10 & 20 & 30\end{array}$
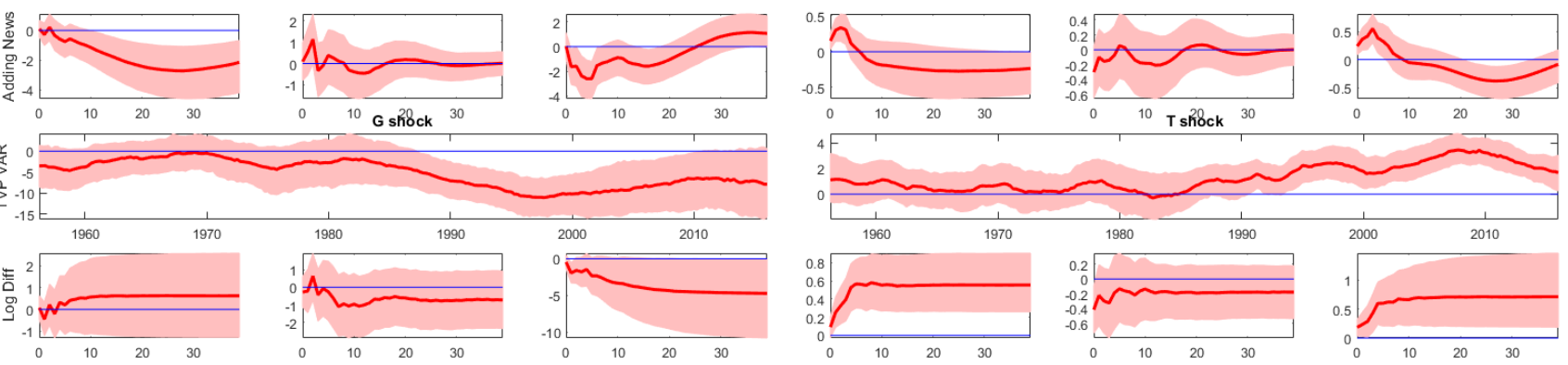

Figure 11: Sensitivity Analysis. Each row presents the response of $S$ to spending and revenue shocks. 


\section{Technical Appendix: Fiscal policy shocks and stock prices in the United States.*}

\author{
Haroon Mumtaz ${ }^{\dagger}$ \\ Queen Mary University
}

Konstantinos Theodoridis ${ }^{\ddagger}$

Bank of England

Lancaster University Management School

January 2017

\section{SVAR Estimation}

\subsection{Recursive VAR, Blanchard and Perotti (2002) VAR and VAR with Sign Re- strictions}

Consider the reduced form VAR

$$
Y_{t}=\alpha \Gamma_{t}+\sum_{j=1}^{P} \beta_{t-j} Y_{t-j}+v_{t}, \operatorname{var}\left(v_{t}\right)=\Omega
$$

where $\Gamma_{t}$ is $1 \times M$ vector of exogenous regressors. We adopt a Bayesian approach to estimation of the reduced form VAR model. We introduce a natural conjugate prior for the VAR parameters (see Banbura et al. (2010)):

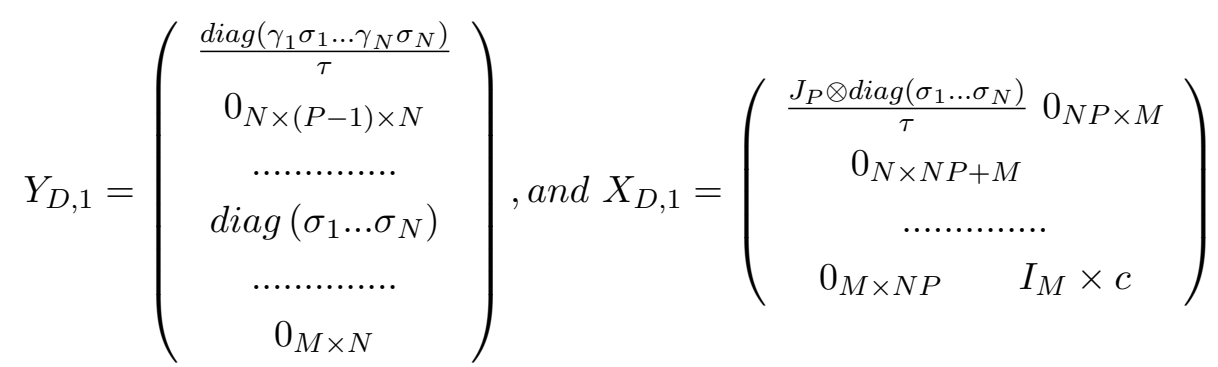

where $\gamma_{1}$ to $\gamma_{N}$ denotes the prior mean for the coefficients on the first lag, $\tau$ is the tightness of the prior on the VAR coefficients and $c$ is the tightness of the prior on the constant terms. In our application, the prior means are chosen as the OLS estimates of the coefficients of an AR(1) regression estimated for each endogenous variable using a training sample. We set a loose prior, $\tau=100000$. The scaling factors $\sigma_{i}$ are set using the standard deviation of the error terms from these preliminary $\operatorname{AR}(1)$ regressions. Finally we set $c=1 / 1000$ in our implementation indicating a flat prior on the

*Any views expressed are solely those of the author(s) and so cannot be taken to represent those of the Bank of England or to state Bank of England policy. This paper should therefore not be reported as representing the views of the Bank of England or members of the Monetary Policy Committee, Financial Policy Committee or Prudential Regulation Authority Board.

${ }^{\dagger}$ Email:h.mumtaz@qmul.ac.uk

${ }^{\ddagger}$ konstantinos.theodoridis@bankofengland.co.uk 
constant. We also introduce a prior on the sum of the lagged dependent variables by adding the following dummy observations:

$$
Y_{D, 2}=\frac{\operatorname{diag}\left(\gamma_{1} \mu_{1} \ldots \gamma_{N} \mu_{N}\right)}{\lambda}, X_{D, 2}=\left(\frac{\left(1_{1 \times P}\right) \otimes \operatorname{diag}\left(\gamma_{1} \mu_{1} \ldots \gamma_{N} \mu_{N}\right)}{\lambda} 0_{N \times M}\right)
$$

where $\mu_{i}$ denotes the sample means of the endogenous variables calculated using the training sample. As in Banbura et al. (2010), the tightness of this sum of coefficients prior is set as $\lambda=10 \tau$. Given the natural conjugate prior, the conditional posterior distributions of the VAR parameters $B=\operatorname{vec}\left(\left[\alpha, \beta_{1} ; \beta_{2} . . ; \beta_{j}\right]\right)$ and $\Omega$ take a simple form and are defined as:

$$
G(B \mid \Omega) \sim N\left(B^{*}, \Omega \otimes\left(X^{* \prime} X^{*}\right)^{-1}\right)
$$

$$
G(\Omega \mid B) \sim I W\left(S^{*}, T^{*}\right) .
$$

where $X$ denotes the right hand side variables $\Gamma_{t}, Y_{t-1}, . . Y_{t-P}$. The posterior means are given by $B^{*}=\left(X^{* \prime} X^{*}\right)^{-1}\left(X^{* \prime} Y^{*}\right)$ and $S^{*}=\left(Y^{*}-X^{*}\right) \tilde{B}^{\prime}\left(Y^{*}-X^{*} \tilde{B}\right)$, where $Y^{*}=\left[Y ; Y_{D, 1} ; Y_{D, 2}\right], X^{*}=\left[X ; X_{D, 1} ; X_{D, 2}\right]$ and $\tilde{B}$ is the draw of the VAR coefficients $B$ reshaped to be conformable with $X^{*}$. T $T^{*}$ denotes the number of rows of $Y^{*}$. A Gibbs sampler offers a convenient method to simulate the posterior distribution of $B$ and $\Omega$ by drawing successively from these conditional posteriors. We employ 25,000 iterations using the last 5000 for inference.

Once the iterations are past the burn-in stage, we draw the contemporaneous impact matrix:

\subsubsection{Recursive SVAR}

In this case $A_{0}=\operatorname{chol}(\Omega)$

\subsubsection{Blanchard and Perotti (2002) VAR}

We add a random walk Metropolis Hastings step to draw $A_{0}$. The structural VAR can be written as 1 .

$$
\left(\begin{array}{ccccccc}
1 & 0 & 0.5 & 0 & 0 & 0 & 0 \\
a_{1} & 1 & 0 & a_{2} & 0 & 0 & 0 \\
a_{3} & a_{4} & 1 & a_{5} & 0 & 0 & 0 \\
0 & -1.85 & -1.25 & 1 & 0 & 0 & 0 \\
a_{6} & a_{7} & a_{8} & a_{9} & 1 & 0 & 0 \\
a_{10} & a_{11} & a_{12} & a_{13} & a_{14} & 1 & 0 \\
a_{15} & a_{16} & a_{17} & a_{18} & a_{19} & a_{20} & 1
\end{array}\right)\left(\begin{array}{c}
v_{G} \\
v_{Y} \\
v_{\pi} \\
v_{T} \\
v_{R} \\
v_{I} \\
v_{S}
\end{array}\right)=
$$

\footnotetext{
${ }^{1}$ The elasticities used in the two sub-samples are given in Perotti $\sqrt{2005}$.
} 


$$
\left(\begin{array}{ccccccc}
b_{1} & 0 & 0 & 0 & 0 & 0 & 0 \\
0 & b_{2} & 0 & 0 & 0 & 0 & 0 \\
0 & 0 & b_{3} & 0 & 0 & 0 & 0 \\
b_{8} & 0 & 0 & b_{4} & 0 & 0 & 0 \\
0 & 0 & 0 & 0 & b_{5} & 0 & 0 \\
0 & 0 & 0 & 0 & 0 & b_{6} & 0 \\
0 & 0 & 0 & 0 & 0 & 0 & b_{7}
\end{array}\right)\left(\begin{array}{c}
u_{G} \\
u_{Y} \\
u_{\pi} \\
u_{T} \\
u_{R} \\
u_{I} \\
u_{S}
\end{array}\right)
$$

The concentrated log likelihood function is defined as

$$
\ln l i k=\frac{T}{2} \ln \left(\operatorname{det}(A)^{2}\right)-\frac{T}{2} \ln \left(\operatorname{det}(B)^{2}\right)-\frac{T}{2} \operatorname{tr}\left(A^{\prime} B^{-1 \prime} B^{-1} A \Omega\right)
$$

Let $\theta=\left(a_{1}, a_{2}, \ldots a_{20}, b_{1}, b_{2}, . . b_{8}\right)$. A candidate value of $\theta$ is drawn from

$$
\theta^{\text {new }}=\theta^{\text {old }}+\xi
$$

where $\xi^{\sim} N(0, c \varpi)$ where $\varpi$ is obtained is the inverse hessian of $\ln l i k$ evaluated at the (local) maximum. As we adopt flat priors, the draw is accepted if $\exp \left(\ln l i k\left(\theta^{\text {new }}\right)-\ln l i k\left(\theta^{\text {old }}\right)\right)>U$ where $U$ is a draw of a standard uniform number. We adjust the scaling factor $c$ to obtain an acceptance rate of about 40\%. Note that $A_{0}=A^{-1} B$

\subsubsection{Sign restrictions}

This section explains briefly the identification scheme employed by Mountford and Uhlig (2009). The sign restrictions describe in Table 1 are imposed for four periods using the penalty function approach developed by Uhlig (2005).

Table 1: Sing Restrictions

\begin{tabular}{l|c|c|c|c}
\hline \hline Variables & \multicolumn{3}{|c}{ Shocks } \\
\hline & Government Spending & Tax & Business Cycle & Monetary Policy \\
\hline \hline Government Spending & + & & & \\
GDP & & & + & + \\
CPI inflation & & + & + & - \\
Government Revenue & & & + & + \\
Short-Term Interest Rate & & & & \\
10-year Government Bond Yield & & & & \\
Real Stock Prices & & & \\
\hline \hline
\end{tabular}

Notes: All sing restrictions have been imposed for 4 periods.

As it has been discussed above the mapping between reduced and structural errors is given by

$$
\omega_{t}=A_{0} v_{t}
$$

For any orthogonal matrix $D\left(D D^{\prime}=I\right.$, where $I$ is the identity matrix $)$ the above mapping can be written as 


$$
\omega_{t}=A_{0} D v_{t}
$$

Since

$$
\Omega=A_{0} D D^{\prime} A_{0}^{\prime}=A_{0} A_{0}^{\prime}
$$

Using the companion form of the $\operatorname{VAR}(\mathrm{p})$ model, the impulse of variable $j$ and the impulse of shock $i$ in the period $h$ can be expressed as

$$
I R F_{i, j}(h)=J_{j} B^{h-1} A_{0} D J_{i}^{\prime}
$$

where $J_{i}$ and $J_{h}$ are selection matrices of zeros and ones.

In Uhlig (2005) the matrix $D$ results from the following minimisation problem

$$
D^{*}=\arg \min \sum_{j \in \mathcal{I}_{+}} \sum_{h_{j}=\tilde{h}_{j}}^{H_{j,+} \in H_{+}} f\left(-\frac{J_{j} B^{h-1} A_{0} D J_{i}^{\prime}}{\sigma_{j}}\right)+\sum_{j \in \mathcal{I}_{-}} \sum_{h_{j}=\tilde{h}_{j}}^{H_{j,+} \in H_{+}} f\left(\frac{J_{j} B^{h-1} A_{0} D J_{i}^{\prime}}{\sigma_{j}}\right)
$$

s.t.

$$
D D^{\prime}=I
$$

where $\sigma_{j}$ is the standard deviation of variable $j$ and $f(x)=\left\{\begin{array}{c}100 x \text { if } x \geq 0 \\ x \text { otherwise }\end{array}\right.$. Finally, $\mathcal{I}_{+}$is the index set of variables, for which identification of a given shock restricts the impulse response to be positive and $\mathcal{I}_{-}$is the index set of variables, for which identification restricts the impulse response to be negative.

\subsection{Proxy SVAR}

Stock and Watson (2008) and Mertens and Ravn (2014) have recently proposed a structural VAR approach that uses proxy variables as instruments rather than additional endogenous variables. The underlying VAR model is given by the following equation:

$$
\tilde{Y}_{t}=c+\sum_{j=1}^{P} B_{j} \tilde{Y}_{t-p}+\tilde{A}_{0} \tilde{\varepsilon}_{t}
$$

The vector of endogenous variables $\tilde{Y}_{t}$ does not contain the constructed measure of fiscal shocks directly but, instead, this is used as an instrument to estimate the structural shock of interest $\varepsilon_{t}^{c}$. Denoting the remaining shocks by $\tilde{\varepsilon}_{t}^{\bullet}$, this approach requires the proxy for fiscal shocks $\hat{\varepsilon}_{t}^{c}$ to satisfy the following conditions

$$
\begin{aligned}
E\left(\hat{\varepsilon}_{t}^{c}, \varepsilon_{t}^{c}\right) & =\alpha \neq 0 \\
E\left(\hat{\varepsilon}_{t}^{c}, \tilde{\varepsilon}_{t}^{\bullet}\right) & =0 \\
\operatorname{VAR}\left(\tilde{\varepsilon}_{t}\right) & =D=\operatorname{diag}\left(\sigma_{\varepsilon_{1 t}}, \ldots \sigma_{\varepsilon_{N t}}\right)
\end{aligned}
$$


The first expression in equation 12 states that the instrument $\hat{\varepsilon}_{t}^{c}$ is correlated with the structural shock to be estimated, while the second expression rules out any correlation between $\hat{\varepsilon}_{t}^{c}$ and the remaining structural shocks and establishes exogeneity of the instrument. The final condition ensures that the shocks are contemporaneously uncorrelated. As shown in Stock and Watson (2008), Mertens and Ravn (2013) and Mertens and Ravn (2014), these conditions along with the requirement that the structural shocks $\tilde{\varepsilon}_{t}$ are contemporaneously uncorrelated can be used to derive a GMM estimator for the column of $\tilde{A}_{0}$ that corresponds to $\hat{\varepsilon}_{t}^{c}$. Letting $\tilde{A}_{0}=\left[\tilde{A}_{0,1} \ldots . \tilde{A}_{0, N}\right]$ and $\tilde{A}_{0} \tilde{\varepsilon}_{t}=u_{t}$ where $\operatorname{VAR}\left(u_{t}\right)=\Omega$. Then Stock and Watson (2008) show that that $\varepsilon_{1 t}$ can be estimated via a regression of $\hat{\varepsilon}_{t}^{c}$ on $u_{t}$. Note that $E\left(u_{t} \hat{\varepsilon}_{t}^{c}\right)=E\left(\tilde{A}_{0} \varepsilon_{t} \hat{\varepsilon}_{t}^{c}\right)=\left[\tilde{A}_{0,1} \ldots . \tilde{A}_{0, N}\right]\left[\begin{array}{c}E\left(\varepsilon_{1 t} \hat{\varepsilon}_{t}^{c}\right) \\ \cdot \\ \cdot \\ E\left(\varepsilon_{N t} \hat{\varepsilon}_{t}^{c}\right)\end{array}\right]=\tilde{A}_{0,1} \alpha$. Let $\Pi$ denote the coefficient on $u_{t}$. Then the fitted value $\Pi u_{t}$ equals the structural shock of interest up to sign and scale:

$$
\begin{aligned}
\Pi u_{t}= & E\left(\hat{\varepsilon}_{t}^{c} u_{t}^{\prime}\right) \Omega^{-1} u_{t} \\
= & \alpha \tilde{A}_{0,1}^{\prime}\left(\tilde{A}_{0} D \tilde{A}_{0}^{\prime}\right)^{-1} u_{t} \\
& \alpha\left(\tilde{A}_{0,1}^{\prime} \tilde{A}_{0}^{-1^{\prime}}\right) D^{-1}\left(\tilde{A}_{0}^{-1} u_{t}\right) \\
= & \frac{\alpha \varepsilon_{1 t}}{D_{11}}
\end{aligned}
$$

where going from the third to the final line uses the fact that $\left(\tilde{A}_{0,1}^{\prime} \tilde{A}_{0}^{-1^{\prime}}\right)=[1,0, \ldots 0]$ and $\tilde{A}_{0}^{-1} u_{t}=\varepsilon_{t}$. Note that equation 12 imposes less stringent conditions on the quality of $\hat{\varepsilon}_{t}^{c}$ than those required for unbiased estimation when the proxy variable is added directly to the VAR model. In particular, the only requirements are that $\hat{\varepsilon}_{t}^{c}$ is correlated with the shock of interest and uncorrelated with other shocks. These conditions can be satisfied even if $\hat{\varepsilon}_{t}^{c}$ is measured with error.

\section{Model}

This section reviews the theoretical model adopted in this study to understand the SVAR stylised facts discussed in the previous section. As in Traum and Yang (2011), we augment the model developed by Christiano et al. (2005) and Smets and Wouters (2007) with a simple non-productive government sector so we can investigate the effects of a government spending shock on the macroeconomic variables.

\section{$2.1 \quad$ Household}

There is a continuum of agents who consume consumption $\left(\tilde{C}_{t}\right)$, supply labour $\left(L_{t}\right)$ and capital services $\left(v_{t} K_{t-1}\right)$. The utility function is given by

$$
U_{t}=E_{t} \sum_{t=0}^{\infty} \beta^{i}\left\{\log \left(\tilde{C}_{t+i}-h \tilde{C}_{t+i-1}\right)-\chi_{t} \frac{L_{t+i}^{1+\sigma_{L}}}{1+\sigma_{L}}\right\}
$$

where $\beta$ denotes the time discount factor, $\sigma_{L}$ is the labour supply elasticity, $h$ is the consumption smoothing parameter and $\chi_{t}$ is a stationary labour supply shock. ${ }^{2}$ Households choose how much to

\footnotetext{
${ }^{2}$ Non stationary variables are denoted with tilde (テ).
} 
consume and to work by maximising the above objective function subject to the following budget constraint

$$
\tilde{C}_{t}+\tilde{I}_{t}+\tilde{B}_{t}=\left(1-\tau_{t}\right) \tilde{W}_{t} L_{t}+\left(1-\tau_{t}\right) R_{t}^{K} v_{t} \tilde{K}_{t-1}-u\left(v_{t}\right) \tilde{K}_{t-1}+\frac{R_{t-1}^{G} \tilde{B}_{t-1}}{\Pi_{t}}+\widetilde{T R}_{t}+\widetilde{\Xi}_{t}
$$

where $\tilde{W}_{t}$ stands for nominal wages, $R_{t}^{K}$ is the rental rate of capital, $v_{t}$ is the degree of capital utilisation, $u(v)$ is the cost of capital utilisation, $R_{t}^{G}$ is the effective interest rate faced by households

$$
R_{t}^{G}=R_{t} \psi_{t}
$$

which is the policy rate times an exogenous risk premium (haircut type) shock $\left(\psi_{t}\right)$ that captures agents' loses from investing on government debt $\left.\left(\tilde{B}_{t}\right)\right]^{3} \widetilde{T R}_{t}$ and $\widetilde{\Xi}_{t}$ denote transfers and profits, while $I_{t}$ is investment used for the accumulation of physical capital

$$
\tilde{K}_{t}=(1-\delta) \tilde{K}_{t-1}+\mu_{t}\left(1-\phi_{I}\left(\frac{\tilde{I}_{t}}{\tilde{I}_{t-1}}\right)\right) \tilde{I}_{t}
$$

This process is subject to a quadratic adjustment $\operatorname{cost}\left(\phi_{I}\left(\frac{\tilde{I}_{t}}{\tilde{I}_{t-1}}\right)\right)$ and investment specific stationary productivity shock $\left(\mu_{t}\right) U^{4} \delta$ is the depreciation rate and $\phi_{I}$ captures the severity of the real friction.

Agents' optimal decisions regarding to consumption, bond, utilisation, capital and investment are given, respectively, by:

$$
\frac{1}{\tilde{C}_{t}-h \tilde{C}_{t-1}}=\tilde{\lambda}_{t}
$$

Where $\tilde{\lambda}$ is the marginal rate of consumption.

$$
\begin{aligned}
& \tilde{\lambda}_{t}=\beta \frac{R_{t}^{G} \tilde{\lambda}_{t+1}}{\Pi_{t+1}} \\
& R_{t}^{K}\left(1-\tau_{t}\right)=u^{\prime}\left(v_{t}\right) \\
& \tilde{q}_{t}=\beta \frac{\tilde{\lambda}_{t+1}}{\tilde{\lambda}_{t}}\left[\left\{\left(1-\tau_{t+1}\right) R_{t+1}^{K} v_{t+1}-u\left(v_{t+1}\right)\right\}+(1-\delta) \tilde{q}_{t+1}\right] \\
& 1=\tilde{q}_{t} \mu_{t}\left\{1-\frac{\phi_{I}}{2}\left(\frac{\tilde{I}_{t}}{\tilde{I}_{t-1}}-\Gamma\right)^{2}-\phi_{I}\left(\frac{\tilde{I}_{t}}{\tilde{I}_{t-1}}-\Gamma\right) \frac{\tilde{I}_{t}}{\tilde{I}_{t-1}}\right\}+\beta \mu_{t+1} \frac{\tilde{\lambda}_{t+1}}{\tilde{\lambda}_{t}} \tilde{q}_{t+1} \phi_{I}\left(\frac{\tilde{I}_{t+1}}{\tilde{I}_{t}}-\Gamma\right)\left(\frac{\tilde{I}_{t+1}}{\tilde{I}_{t}}\right)^{2}
\end{aligned}
$$

\footnotetext{
${ }^{3}$ This is the shock that Smets and Wouters (2007) call a reduced-form net-worth shock.

${ }^{4}$ Although it is not stated explicitly, we follow the literature and we assume that households have access to ArrowDebru security that individual consumption risks and give rise to a unique budge constraint.
} 


\subsection{Wages}

We follow Erceg et al. (2000) and assume that each monopolistically competitive household supplies a differentiated labour service to the production section. They set their nominal wage and supply any amount of labour demanded by the firms at that wage rate. For convenience, we assume that there exist a representative firm that combines households' labour inputs into a homogenous input hood $L_{t}^{d}$ - using a CES production function

$$
L_{t}^{d}=\left[\int_{0}^{1}\left(L_{t}(\kappa)\right)^{\frac{1}{\lambda_{w}}} d \kappa\right]^{\lambda_{w}}
$$

where $\lambda_{w}$ is the mark-up in the labour market. Taking $w_{t}$ and $w_{\kappa, t}$ as given the aggregator's demand for the labour hours of household $\kappa$ results its profit maximisation $\max _{h_{\kappa, t}}\left\{\tilde{w}_{t}\left[\int_{0}^{1}\left(L_{t}(\kappa)\right)^{\frac{1}{\lambda_{w}}} d \kappa\right]^{\lambda_{w}}-\int_{0}^{1} \tilde{w}_{t}(\kappa) L_{t}(\kappa)\right\}$

$$
L_{t}(\kappa)=\left(\frac{\tilde{w}_{t}(\kappa)}{\tilde{w}_{t}}\right)^{-\frac{\lambda w}{\lambda w-1}} L_{t}^{d}
$$

The aggregate wage arise from the profit condition and the demand curve

$$
\tilde{w}_{t}=\left[\int_{0}^{1}\left(\tilde{w}_{t}(\kappa)\right)^{\frac{1}{1-\lambda} w} d \kappa\right]^{1-\lambda_{w}}
$$

In each period, a function $-1-\xi_{w}$ - of households receive a random signal and they are allowed to reset wages optimally $-w_{t}^{\text {new }}$. All other households can only partially index their wages by past inflation. The problem of setting wages can be described as follows

$$
\max _{w_{t}^{\text {new }}} E_{t} \sum_{j=0}^{\infty}\left(\beta \xi_{w}\right)^{j}\left\{-\chi_{t} \frac{\left(L_{t+j}(\kappa)\right)^{1+\sigma_{L}}}{1+\sigma_{L}}+\lambda_{t+j} \prod_{s=1}^{j} \frac{\Pi_{t+s-1}^{\iota_{w}} \Pi^{1-\iota_{w}}}{\Pi_{t+s}}\left(1-\tau_{t+j}\right) \tilde{w}_{t+j}(\kappa) L_{t+j}(\kappa)\right\}
$$

subject to

$$
L_{t+j}(\kappa)=\left(\prod_{s=1}^{j} \frac{\Pi_{t+s-1}^{\iota w} \Pi^{1-\iota_{w}}}{\Pi_{t+s}} \frac{w_{t}(\kappa)}{w_{t+j}}\right)^{-\frac{\lambda_{w, t+j}}{\lambda_{w, t+j}-1}} L_{t+j}^{d}
$$

The first order is summarised by the following recursive equations

$$
\begin{aligned}
\tilde{v}_{t} & =\tilde{\lambda}_{t} \frac{1}{\lambda_{w}}\left(\tilde{w}_{t}^{\text {new }}\right)^{\frac{1}{1-\lambda_{w}}} \tilde{w}_{t}^{\frac{\lambda_{w}}{\lambda_{w}-1}}\left(1-\tau_{t}\right) L_{t}^{d}+\beta \xi_{w} E_{t}\left(\frac{\Pi_{t}^{\iota w} \Pi^{1-\iota_{w}}}{\Pi_{t+1}}\right)^{\frac{1}{1-\lambda_{w}}}\left(\frac{\tilde{w}_{t+1}^{\text {new }}}{\tilde{w}_{t}^{\text {new }}}\right)^{\frac{1}{\lambda_{w}-1}} \tilde{v} \\
\tilde{v}_{t} & =\chi_{t}\left(\frac{\tilde{w}_{t}}{\tilde{w}_{t}^{n e w}}\right)^{\frac{(1+\sigma) \lambda w}{\lambda_{w}-1}}\left(L_{t}^{d}\right)^{1+\sigma}+\beta \xi_{w} E_{t}\left(\frac{\Pi_{t}^{\iota_{w}} \Pi^{1-\iota_{w}}}{\Pi_{t+1}}\right)^{\frac{(1+\sigma) \lambda_{w}}{1-\lambda_{w}}}\left(\frac{\tilde{w}_{t+1}^{\text {new }}}{\tilde{w}_{t}^{\text {new }}}\right)^{\frac{(1+\sigma) \lambda w}{\lambda_{w}-1}} \tilde{v}_{t+1} \\
\tilde{w}_{t}^{\frac{1}{1-\lambda_{w}}} & =\xi_{w}\left(\frac{\Pi_{t-1}^{\iota_{w}} \Pi^{1-\iota_{w}}}{\Pi_{t}}\right)^{\frac{1}{1-\lambda w}} \tilde{w}_{t-1}^{\frac{1}{1-\lambda w}}+\left(1-\xi_{w}\right)\left(\tilde{w}_{t}^{n e w}\right)^{\frac{1}{1-\lambda w}}
\end{aligned}
$$




\subsection{Intermediate Firms}

Again there is a continuum of intermediate producers that employ labour and capital services to produce using the the following technology

$$
\tilde{Y}_{t}=\alpha_{t}\left(\tilde{Z}_{t} L_{t}\right)^{1-\phi}\left(v_{t} K_{t-1}\right)^{\phi}
$$

a product that is bought by the final producer. $\alpha_{t}$ is a stationary productivity shock, while $\tilde{Z}_{t}$ is the stochastic trend and $\phi$ is the capital share. Intermediate producers operate in two stages, firstly, they take wage and rental rate of capital a given and decide about labour and capital demand by maximising their profit:5

$$
\begin{aligned}
& \tilde{\Xi}_{I, t}=\tilde{Y}_{t}-\tilde{W}_{t} L_{t}-R_{t}^{K} v_{t} K_{t-1}-M C_{t}\left\{\tilde{Y}_{t}-\left(\tilde{Z}_{t} L_{t}\right)^{1-\phi}\left(v_{t} K_{t-1}\right)^{\phi}\right\} \\
& M C_{t}=\frac{\tilde{W}_{t}}{(1-\phi) \frac{\tilde{Y}_{t}}{L_{t}}} \\
& M C_{t}=\frac{R_{t}^{K} v_{t}}{\phi \frac{\tilde{Y}_{t}}{\tilde{K}_{t-1}}}
\end{aligned}
$$

In the second stage, they decide about what price to charge. To be precise, a fraction $-\left(1-\xi_{p}\right)-$ of intermediate firms receive a random signal and they are allowed to optimally reset their prices $-p_{i, t}^{n e w}$. The proportion $-\xi_{p}$ - of firms that cannot reoptimise prices will set $p_{t}$ based on backward-looking rule

$$
P_{t}=\left(\Pi_{t-1}\right)^{\kappa_{p}} \Pi^{1-\kappa_{p}} P_{t-1}
$$

where $\pi_{t}=\frac{p_{t}}{p_{t-1}}$ is the gross inflation and $\kappa_{p}$ is the indexation parameter. The pricing problem of firm $i$ is then

$$
\max _{p_{i, t}^{n e w}} E_{t} \sum_{j=0}^{\infty}\left(\beta \xi_{p}\right)^{j} \frac{\tilde{\lambda}_{t+j}}{\tilde{\lambda}_{t}}\left\{\left(\prod_{s=1}^{j} \Pi_{t+s-1}^{\kappa_{p}} \Pi^{1-\kappa_{p}} \frac{P_{i, t}^{\text {new }}}{P_{t+j}}-M C_{t+j}\right) Y_{i, t+j}\right\}
$$

subject to

$$
\tilde{Y}_{i, t+j}=\left(\prod_{s=1}^{j} \Pi_{t+s-1}^{\kappa_{p}} \Pi^{1-\kappa_{p}} \frac{P_{i, t}^{\text {new }}}{P_{t+j}}\right)^{-\frac{\lambda_{p}}{\lambda_{p}-1}} \tilde{Y}_{t+j}^{d}
$$

\footnotetext{
${ }^{5}$ Again we follow the literature and assume that capital is distributed across firms so they all face the same marginal cost.
} 
The first-order condition is expressed as system of difference equations

$$
\begin{aligned}
F_{1, t} & =\tilde{\lambda}_{t} M C_{t} \tilde{Y}_{t}^{d}+\beta \xi_{p} E_{t}\left(\frac{\Pi_{t}^{\kappa_{p}} \Pi^{1-\kappa_{p}}}{\Pi_{t+1}}\right)^{-\frac{\lambda_{p}}{\lambda_{p}-1}} F_{1, t+1} \\
F_{2, t} & =\tilde{\lambda}_{t} \bar{\Pi}_{t} \tilde{Y}_{t}^{d}+\beta \xi_{d} E_{t}\left(\frac{\Pi_{t}^{\kappa_{p}} \Pi^{1-\kappa_{p}}}{\Pi_{t+1}}\right)^{-\frac{1}{\lambda_{p}-1}}\left(\frac{\bar{\Pi}_{t}}{\bar{\Pi}_{t+1}}\right) F_{2, t+1} \\
0 & =\lambda_{p} F_{1, t}-F_{2, t} \\
1 & =\xi_{p}\left(\frac{\Pi_{t-1}^{\kappa_{p}} \Pi^{1-\kappa_{p}}}{\Pi_{t}}\right)^{-\frac{1}{\lambda_{p}-1}}+\left(1-\xi_{p}\right) \bar{\Pi}_{t}^{-\frac{1}{\lambda_{p}-1}}
\end{aligned}
$$

where $\bar{\Pi}_{t} \equiv \frac{P_{t}^{\text {new }}}{P_{t}}$.

\subsection{Government}

Fiscal authorities finance government consumption and transfers by rising revenues from taxation and issuing new debt. Both (tax and debt) decisions are based on simple rules

$$
\begin{aligned}
& \frac{\tilde{B}_{t}}{R_{t}^{G}}+\tau_{t}\left(R_{t}^{K} v_{t} \tilde{K}_{t-1}+\tilde{W}_{t} L_{t}\right)=\frac{\tilde{B}_{t-1}}{\Pi_{t}}+\tilde{G}_{t}+\widetilde{T R}_{t} \\
& \frac{\tau_{t}}{\tau}=\left(\frac{\tau_{t-1}}{\tau}\right)^{\rho_{\tau}}\left(\frac{\tilde{B}_{t-1}}{\tilde{Y}_{t-1}} / \frac{B}{Y}\right)^{\left(1-\rho_{\tau}\right) \zeta_{\tau}}
\end{aligned}
$$

while proportion of final output consumed by the government follows a stationary exogenous process

$$
\frac{\tilde{G}_{t} Z}{\tilde{Z}_{t} G}=\left(\frac{\tilde{G}_{t-1} Z}{\tilde{Z}_{t-1} G}\right)^{\rho_{g}} \exp ^{\sigma_{g} \epsilon_{g, t}}
$$

As it is discussed in Leeper (1991), a fiscal authority is characterised as 'passive' when it sets taxes in a way that 'restores' debt back to its steady sate value. This is achieved by setting $\zeta_{\tau}$ greater than $\frac{\Pi \Gamma}{\beta}-1$. When authorities' tax reaction function does not satisfy the latter condition $\left(\zeta_{\tau}<\frac{\Pi \Gamma}{\beta}-1\right)$, then they actively destabilise the debt.

The monetary policy reaction function is given by

$$
\frac{R_{t}}{R}=\left(\frac{R_{t-1}}{R}\right)^{\rho_{R}}\left(\frac{\Pi_{t}}{\Pi}\right)^{\left(1-\rho_{R}\right) \gamma_{\pi}}\left(\frac{Y_{t}}{Y}\right)^{\left(1-\rho_{R}\right) \gamma_{y}} \exp ^{\sigma_{R} \varepsilon_{R, t}}
$$

Similarly, the monetary policy is considered as passive if the policy rate does not respond to changes in the inflation strong enough to stabilise inflation expectations $\left(\gamma_{\pi}<1\right)$. When $\gamma_{\pi}>1$ monetary policy is viewed as active since it guarantees that the long run inflation expectation coincide with the inflation target. 


\subsection{Market Clearing Conditions}

Market clearing condition in the final sector is

$$
Y_{t}=\alpha_{t} L_{t}^{1-\phi}\left(v_{t} \frac{K_{t-1}}{\Gamma_{t}}\right)^{\phi}=\int_{0}^{1} Y_{i, t} d i=\int_{0}^{1}\left(\frac{P_{i, t}}{P_{t}}\right)^{-\frac{\lambda_{p}}{\lambda_{p}-1}} d i Y_{t}^{d}=v_{t}^{p} Y_{t}^{d}=v_{t}^{p}\left(c_{t}+i_{t}+u\left(v_{t}\right) \frac{K_{t-1}}{\Gamma_{t}}\right)
$$

where $v_{t}^{p}=\int_{0}^{1}\left(\frac{p_{i, t}}{p_{t}}\right)^{-\frac{\lambda_{d, t}}{\lambda_{d, t^{-1}}}} d_{i}$ is the price dispersion term and it is given by

$$
v_{t}^{p}=\xi_{p}\left(\frac{\Pi_{t-1}^{\kappa_{p}} \Pi^{1-\kappa_{p}}}{\Pi_{t}}\right)^{-\frac{\lambda_{p}}{\lambda_{p}-1}} v_{t-1}^{p}+\left(1-\xi_{p}\right) \bar{\Pi}_{t}^{-\frac{\lambda_{p}}{\lambda_{p}-1}}
$$

The market clearing condition in the labour market is

$$
L_{t}=\int_{0}^{1} L_{\kappa, t} d \kappa=v_{t}^{w} L_{t}^{d}
$$

where $v_{t}^{w}=\int_{0}^{1}\left(\frac{w_{i, t}}{w_{t}}\right)^{-\frac{\lambda_{w}}{\lambda_{w}-1}} d_{i}$ is the wage dispersion term and its evolution is described

$$
v_{t}^{w}=\xi_{w}\left(\frac{\Pi_{t-1}^{\iota_{w}} \bar{\Pi}_{t}^{1-\iota_{w}}}{\Pi_{t}}\right)^{\frac{\lambda_{w}}{1-\lambda_{w}}}\left(\frac{\tilde{w}_{t-1}}{\tilde{w}_{t}}\right)^{\frac{\lambda_{w}}{1-\lambda_{w}}} v_{t-1}^{w}+\left(1-\xi_{w}\right)\left(\frac{\tilde{w}_{t}^{n e w}}{\tilde{w}_{t}}\right)^{\frac{\lambda_{w}}{1-\lambda_{w}}}
$$

\subsection{Equity Price}

Similar to Swanson (2015), an equity security is defined as a levered claim on the aggregate consumption. As it is explained Swanson (2015), this choice is motivated by the fact it maximises te comparability to the finance literature (Campbell and Cochrane (1999), Campbell (2003)). Every period, the equity pays a dividend equal to $c_{t}^{\vartheta}$ where $\vartheta$ captures the degree of leverage. In this case the price of the equity is defined as

$$
q_{e, t}=E_{t} m_{t+1}\left(c_{t+1}^{\vartheta}+q_{e, t+1}\right)
$$

where $m_{t}$ is the stochastic discount factor.

\subsection{Calibrated Parameters}

The model is estimated using full information Bayesian Maximum Likelihoood technique, however, a small number of structural parameters - summarised by Table 2 - is actually calibrated prior to the estimation of the model. To be precise, the share of capital in the production $(\phi)$ and its depreciation rate $(\delta)$ have been calibrated to 0.36 and 0.025 , numbers typically used in the literature (Christiano et al. (2005), Trabandt and Uhlig (2011) and Jermann and Quadrini (2012)). As in Smets and Wouters (2007) we assume that steady-state price $\left(\lambda_{p}\right)$ and wage $\left(\lambda_{w}\right)$ markups are equal to $20 \%$. The calibration of the steady state value of the debt to GDP ration $\left(\frac{B}{Y}=0.35\right)$, average tax rate $(\tau=0.20)$ and government spending to GDP $\operatorname{ratio}\left(\frac{G}{Y}=0.18\right)$ is based on the studies of Leeper et al. $(2010)$, 
Table 2: Calibrated Parameters

\begin{tabular}{llc}
\hline \hline Mnemonic & Description & Value \\
\hline \hline$\sigma_{L}$ & Inverse Labour Supply Elasticity & 1.00 \\
$\beta$ & Time Discount Factor & 0.99 \\
$\phi$ & Capital Share & 0.36 \\
$\delta$ & Capital Depreciation Rate & 0.03 \\
$\tau$ & Steady State Tax Rate to GDP Ratio & 0.20 \\
$\lambda_{p}$ & Steady State Price Markup & 1.20 \\
$L$ & Steady State Hours & 0.33 \\
$G$ & Steady State Government Spending to GDP Ratio & 0.18 \\
$\lambda_{w}$ & Steady State Wage Markup & 1.20 \\
$B$ & Steady State Debt to GDP Ratio & 0.35 \\
$\vartheta$ & Degree of Leverage & 3.00 \\
\hline \hline
\end{tabular}

Traum and Yang (2011) and Smets and Wouters (2007). The degree of leverage $(\vartheta)$ is set equal to 3 similar to Bansal and Yaron (2004), Campbell et al. (2014) and Swanson (2015). Finally, the values the time discount factor $(\beta=0.99)$, the steady state value of hours $(L=1 / 3)$ and the (inverse) labour supply elasticity $\left(\sigma_{L}=1\right)$ are common choices in the literature.

\subsection{Prior Distributions}

Table 3 summarise the prior density probability function of the estimated parameters. Again, these choices are in line with those used in the literature ( Smets and Wouters (2007), Justiniano et al. (2010) Traum and Yang (2011) among others) and we do not discuss them further here. It is perhaps worthwhile to mentioned that the specification of the prior distribution of $\gamma_{\pi}$ and $\zeta_{\tau}$ permits (fiscal and monetary) policies to be either active or passive.

In addition, we follow Del Negro and Schorfheide (2008), Liu et al. (2013) and Christiano et al. (2011) (among others) and form our priors 'endogenously'. This requires another set of 'priors' that reflect our beliefs regarding selected data moments. These moments are the responses of the set of the observable variables on a government spending shock. This approach offers a natural way to link the SVAR results with the DSGE analysis as the data counterpart of these moments are those estimated by the identified VAR model.

As explained in Del Negro and Schorfheide (2008), eliciting priors are derived by combining Bayesian techniques and calibration approaches. This intuitive approach formalises the decisions most researchers make when deciding the prior moments of the estimated structural parameters. We briefly outline the main idea here, though interested readers are advised to explore the preceding references. Let $\mathcal{M}(\theta)$ denote a vector of DSGE model-implied data moments (expressed as function of the structural parameters vector $\theta$ ) and $\widehat{\mathcal{M}}$ its empirical counterpart. Let us further assume that two vectors of moments are the same up to a vector of measurement errors $\mathcal{V}$

$$
\widehat{\mathcal{M}}=\mathcal{M}(\theta)+\mathcal{V}
$$

Then, as explained in Del Negro and Schorfheide (2008), a conditional distribution that reflects the beliefs about the above moment conditions can be obtained by combining the conditional density of 
Table 3: Estimated Parameters: Prior Moments

\begin{tabular}{|c|c|c|c|c|}
\hline Mnemonic & Description & Density & Mean & STD \\
\hline $100 \log (\Pi)$ & Inflation Target & Gamma & 0.50 & 0.10 \\
\hline $100 \gamma$ & Steady State Growth Trend & Normal & 0.50 & 0.03 \\
\hline$h$ & Consumption Smoothing & Beta & 0.50 & 0.10 \\
\hline$\phi_{I}$ & Investment Adjustment Cost & Gamma & 4.00 & 1.00 \\
\hline$\xi_{p}$ & Calvo Price No Reset Probability & Beta & 0.66 & 0.10 \\
\hline$\iota_{p}$ & Price Indexation & Beta & 0.50 & 0.15 \\
\hline$\xi_{w}$ & Calvo Wage No Reset Probability & Beta & 0.66 & 0.10 \\
\hline$\iota_{w}$ & Wage Indexation & Beta & 0.50 & 0.15 \\
\hline$\kappa_{2}$ & Utilisation Cost Elasticity & Gamma & 5.00 & 1.00 \\
\hline$\zeta_{\tau}$ & Tax Debt to GDP Ration Reaction & Gamma & 0.10 & 0.05 \\
\hline$\rho_{R}$ & Policy Rate Smoothing & Beta & 0.50 & 0.20 \\
\hline$\gamma_{\pi}$ & Policy Reaction to Inflation & Normal & 1.25 & 0.25 \\
\hline$\gamma_{y}$ & Policy Reaction to Output & Gamma & 0.12 & 0.05 \\
\hline$\rho_{\tau}$ & Tax Persistence & Beta & 0.50 & 0.20 \\
\hline$\rho_{g}$ & Government Spending Persistence & Beta & 0.50 & 0.20 \\
\hline$\rho_{\gamma}$ & Persistence Non-Stationary Growth Productivity Process & Beta & 0.50 & 0.20 \\
\hline$\rho_{\psi}$ & Persistence Risk Premium Process & Beta & 0.50 & 0.20 \\
\hline$\rho_{\alpha}$ & Persistence Stationary Productivity Process & Beta & 0.50 & 0.20 \\
\hline$\rho_{\chi}$ & Persistence Labour Supply Process & Beta & 0.50 & 0.20 \\
\hline$\rho_{\mu}$ & Persistence Investment Specific Process & Beta & 0.50 & 0.20 \\
\hline$\sigma_{g}$ & Government Spending Uncertainty & Inv-Gamma & 0.10 & 2.00 \\
\hline$\sigma_{\gamma}$ & STD Non-Stationary Growth Productivity Process & Inv-Gamma & 0.10 & 2.00 \\
\hline$\sigma_{\psi}$ & STD Policy Exogenous Process & Inv-Gamma & 0.10 & 2.00 \\
\hline$\sigma_{\alpha}$ & STD Stationary Productivity Process & Inv-Gamma & 0.10 & 2.00 \\
\hline$\sigma_{\chi}$ & STD Labour Supply Process & Inv-Gamma & 0.10 & 2.00 \\
\hline$\sigma_{\mu}$ & STD Investment Specific Process & Inv-Gamma & 0.10 & 2.00 \\
\hline$\sigma_{R}$ & STD Risk Premium Process & Inv-Gamma & 0.10 & 2.00 \\
\hline
\end{tabular}

Notes: STD denotes the standard deviation and Inv-Gamma the inverse gamma distribution.

$50, \mathcal{L}(\mathcal{M}(\theta) \mid \widehat{\mathcal{M}})$, Bayes theorem, and the primitive prior distribution of the structural parameter vector:

$$
p(\theta \mid \widehat{\mathcal{M}}) \propto \mathcal{L}(\mathcal{M}(\theta) \mid \widehat{\mathcal{M}}) \pi(\theta)
$$

There are several advantages of using this type of prior. For instance, as we can infer from (51), structural parameters are no longer treated as independent, as is typically assumed in the DSGE literature. Furthermore, shock processes are unobserved variables which makes it difficult to justify beliefs regarding the persistence and the volatility of these exogenous processes. In this setup this is not a problem, since these prior moments adjust endogenously to 'match' the selected data moments. Finally, the empirical application in Del Negro and Schorfheide (2008) suggests that these priors can be helpful when DSGE parameters are not well identified.

In our exercise the small size of the two sub-samples impose further, and perhaps more severe, constraints on the estimation of the theoretical model that we hope that these could be alleviated by the prior information summarised in the vector of responses to a government spending shock $(\mathcal{M}(\theta))$. Consistently with the asymptotic theory (Newey and McFadden (1986), Theodoridis (2011)) and other researchers (Christiano et al. (2005), Christiano et al. (2010), Christiano et al. (2016)), we assume 
that $\mathcal{M}(\theta)_{i, j}$ is normally distributed with mean $\widehat{\mathcal{M}}_{i, j}$ and standard deviation $0.1 \sigma_{\widehat{\mathcal{M}}_{i, j}}$. The estimated moments $\left(\widehat{\mathcal{M}}_{i, j}\right.$ and $\left.\sigma_{\widehat{\mathcal{M}}_{i, j}}\right)$ are obtained from the posterior distribution of the SVAR responses

$$
\mathcal{M}(\theta)_{i, j} \sim N\left(\widehat{\mathcal{M}}_{i, j}, 0.1 \sigma_{\widehat{\mathcal{M}}_{i, j}}\right)
$$

Clearly, these probability distributions are 'shrunken' around the estimated mean and this reflects the fact that all the SVAR models considered in the previous section lead to the same conclusion. In other words, our tight prior distributions echo the robust SVAR evidence about the effect of a government spending shock on macro and financial variables. ${ }^{6}$

\subsection{Posterior Estimation}

Table 4: Estimated Parameters: Posterior Moments

\begin{tabular}{l|ccc|ccc}
\hline \hline & \multicolumn{3}{|c|}{$1955 Q 4-1979 Q 4$} & \multicolumn{3}{c}{$1980 Q 1-2007 Q 4$} \\
\hline Mnemonic & Mode & $5^{\text {th }}$ & $95^{\text {th }}$ & Mode & $5^{\text {th }}$ & $95^{\text {th }}$ \\
\hline \hline $100 \log (\Pi)$ & 0.503 & 0.347 & 0.672 & 0.506 & 0.341 & 0.680 \\
$100 \gamma$ & 0.498 & 0.450 & 0.538 & 0.478 & 0.431 & 0.531 \\
$h$ & 0.532 & 0.466 & 0.661 & 0.690 & 0.643 & 0.746 \\
$\phi_{I}$ & 3.112 & 2.386 & 4.777 & 6.151 & 5.632 & 9.017 \\
$\xi_{p}$ & 0.856 & 0.835 & 0.874 & 0.936 & 0.921 & 0.940 \\
$\iota_{p}$ & 0.212 & 0.121 & 0.361 & 0.055 & 0.022 & 0.105 \\
$\xi_{w}$ & 0.808 & 0.779 & 0.850 & 0.825 & 0.772 & 0.867 \\
$\iota_{w}$ & 0.696 & 0.515 & 0.860 & 0.457 & 0.294 & 0.718 \\
$\kappa_{2}$ & 4.682 & 3.253 & 6.460 & 4.662 & 3.144 & 6.442 \\
$\zeta_{\tau}$ & 0.009 & 0.003 & 0.017 & 0.063 & 0.026 & 0.076 \\
$\rho_{R}$ & 0.718 & 0.647 & 0.791 & 0.705 & 0.720 & 0.806 \\
$\gamma_{\pi}$ & 0.480 & 0.365 & 0.581 & 1.618 & 1.498 & 1.866 \\
$\gamma_{y}$ & 0.096 & 0.079 & 0.123 & 0.039 & 0.028 & 0.075 \\
$\rho_{\tau}$ & 0.504 & 0.162 & 0.823 & 0.528 & 0.200 & 0.864 \\
$\rho_{g}$ & 0.765 & 0.741 & 0.785 & 0.999 & 0.999 & 0.999 \\
$\rho_{\gamma}$ & 0.261 & 0.136 & 0.417 & 0.121 & 0.033 & 0.213 \\
$\rho_{\psi}$ & 0.943 & 0.886 & 0.968 & 0.996 & 0.991 & 0.999 \\
$\rho_{\alpha}$ & 0.814 & 0.751 & 0.862 & 0.881 & 0.819 & 0.917 \\
$\rho_{\chi}$ & 0.989 & 0.977 & 0.993 & 0.977 & 0.961 & 0.989 \\
$\rho_{\mu}$ & 0.779 & 0.632 & 0.849 & 0.542 & 0.414 & 0.739 \\
$\sigma_{g}$ & 3.497 & 3.091 & 4.025 & 2.724 & 2.381 & 2.995 \\
$\sigma_{\gamma}$ & 0.552 & 0.491 & 0.644 & 0.695 & 0.642 & 0.809 \\
$\sigma_{\psi}$ & 0.417 & 0.325 & 0.668 & 0.147 & 0.115 & 0.205 \\
$\sigma_{\alpha}$ & 0.898 & 0.794 & 1.043 & 0.662 & 0.607 & 0.756 \\
$\sigma_{\chi}$ & 1.566 & 1.161 & 2.986 & 7.250 & 6.408 & 9.935 \\
$\sigma_{\mu}$ & 2.688 & 1.994 & 4.417 & 5.956 & 4.051 & 8.614 \\
$\sigma_{R}$ & 0.201 & 0.181 & 0.233 & 0.238 & 0.161 & 0.207 \\
\hline \hline & & & & & & \\
\hline
\end{tabular}

Table 4 reports from the estimation of the DSGE model over the two sub-samples $(1955 Q 4-1979 Q 4$ and $1980 Q 1-2015 Q 4) .7$ The vector of the observable variables is the one used by Smets and Wouters

\footnotetext{
${ }^{6}$ The decrease of the estimated variance is our 'brute force' approach to eliminate estimation uncertainty.

${ }^{7}$ The estimation of the model has been carried out using Dynare 4.4.3. The Dynare endogenous prior function has been modified to implement the procedure discussed in the previous section. All the codes can be downloaded from authors' web page.
} 
(2007), namely, GDP growth, consumption growth, investment growth, real wage growth, average hours, inflation and the policy rate ${ }^{8}$

Although the split of the sample is based on prior information related to changes in the presidency of the FED (see Cogley et al. (2010), Lubik and Schorfheide (2004) among others), there are many studies in the literature (Traum and Yang (2011), Leeper et al. (2015), Kliem et al. (2016) among others) that adopt a very similar sub-sample analysis to investigate simultaneous changes in the preferences of both fiscal and monetary authorities. Furthermore, the studies of Bianchi and Ilut (2014) and Bianchi and Melosi (2017) seem to justify empirically a very similar split of the data. Their methodology allows the policy parameters to evolve stochastically from one regime to another. Although the process that 'drives' these switches is unobserved, it can be inferred from the data by using filtering techniques. This analysis reveals that the time period of changes in the policy parameters seems to coincide with the split of the sample adopted in the literature.

Table 4 reveals a very interesting pattern, monetary policy turns from 'passive' in the first part of the sample to 'active' in the second part of the sample. This change is associated with a 'flatter' Philips curve (resetting prices less frequently and less degree of indexation), which would be consistent with the view that inflation expectations are better 'anchored' between $1980 Q 1-2015 Q 4$. Similarly, fiscal policy also switches from 'active' in period 1955Q4 - 1979Q4 to 'passive' in the second part of the sample. This result is consistent with the analysis of Bianchi and Ilut (2014) and Bianchi and Melosi (2017) who also provide evidence about the switch between passive-monetary \& active-fiscal policy regime to active-monetary \& passive-fiscal policy regime around the same time period.

The rest of the estimates fall well in the range of parameters reported in the literature (Christiano et al. (2005), Smets and Wouters (2007), Justiniano et al. (2010), Del Negro et al. (2015) among others) and, therefore, not discussed again here $9^{9}$

\subsection{Sensitivity to Prior Distributions}

This section illustrates that the results are not 'sensitive' to the specification of (52). The sub sample estimation of the DSGE model is also carried out in this section, however, the specification of 'endogenous' prior distribution is 'loser'

$$
\mathcal{M}(\theta)_{i, j} \sim N\left(\widehat{\mathcal{M}}_{i, j}, 0.25 \sigma_{\widehat{\mathcal{M}}_{i, j}}\right)
$$

Table 5 and Figures 1- 2 reveal only marginal changes in the posterior distribution of the structural parameter vector and agents' optimal responses to a government spending shock.

\footnotetext{
${ }^{8}$ The definitions of the series is the same, we have simply updated Smets and Wouters (2007) spreadsheet till $2015 Q 4$.

${ }^{9}$ The model has not been linearised around a deterministic steady-state and the structural disturbances have not been normalised like those in the above mentioned studies and this explains why the standard deviation estimates are different.
} 
Table 5: Estimated Parameters: Posterior Moments (Loser Prior)

\begin{tabular}{l|ccc|ccc}
\hline \hline & \multicolumn{3}{|c|}{$1955 Q 4-1979 Q 4$} & \multicolumn{3}{c}{$1980 Q 1-2007 Q 4$} \\
\hline Mnemonic & Mode & $5^{\text {th }}$ & $95^{\text {th }}$ & Mode & $5^{\text {th }}$ & $95^{\text {th }}$ \\
\hline \hline $100 \log (\Pi)$ & 0.501 & 0.354 & 0.698 & 0.500 & 0.343 & 0.665 \\
$100 \gamma$ & 0.499 & 0.454 & 0.545 & 0.484 & 0.439 & 0.537 \\
$h$ & 0.548 & 0.488 & 0.686 & 0.660 & 0.610 & 0.720 \\
$\phi_{I}$ & 3.571 & 2.671 & 5.210 & 5.549 & 4.829 & 8.378 \\
$\xi_{p}$ & 0.874 & 0.851 & 0.897 & 0.934 & 0.916 & 0.939 \\
$\iota_{p}$ & 0.147 & 0.078 & 0.273 & 0.059 & 0.026 & 0.117 \\
$\xi_{w}$ & 0.832 & 0.802 & 0.873 & 0.823 & 0.787 & 0.876 \\
$\iota_{w}$ & 0.612 & 0.419 & 0.812 & 0.513 & 0.332 & 0.759 \\
$\kappa_{2}$ & 4.686 & 3.324 & 6.467 & 4.677 & 3.270 & 6.427 \\
$\zeta_{\tau}$ & 0.010 & 0.004 & 0.018 & 0.046 & 0.024 & 0.046 \\
$\rho_{R}$ & 0.700 & 0.630 & 0.797 & 0.706 & 0.728 & 0.816 \\
$\gamma_{\pi}$ & 0.557 & 0.395 & 0.683 & 1.695 & 1.562 & 1.907 \\
$\gamma_{y}$ & 0.101 & 0.081 & 0.133 & 0.061 & 0.057 & 0.127 \\
$\rho_{\tau}$ & 0.503 & 0.177 & 0.844 & 0.504 & 0.180 & 0.866 \\
$\rho_{g}$ & 0.782 & 0.755 & 0.811 & 0.998 & 0.998 & 0.998 \\
$\rho_{\gamma}$ & 0.242 & 0.121 & 0.394 & 0.119 & 0.029 & 0.202 \\
$\rho_{\psi}$ & 0.949 & 0.892 & 0.972 & 0.995 & 0.987 & 0.999 \\
$\rho_{\mu}$ & 0.776 & 0.628 & 0.850 & 0.622 & 0.571 & 0.862 \\
$\rho_{\alpha}$ & 0.833 & 0.761 & 0.881 & 0.881 & 0.804 & 0.916 \\
$\rho_{\chi}$ & 0.987 & 0.972 & 0.992 & 0.976 & 0.963 & 0.989 \\
$\sigma_{g}$ & 3.497 & 3.075 & 4.030 & 2.715 & 2.394 & 2.969 \\
$\sigma_{\gamma}$ & 0.546 & 0.487 & 0.632 & 0.698 & 0.639 & 0.799 \\
$\sigma_{\psi}$ & 0.368 & 0.286 & 0.653 & 0.177 & 0.140 & 0.231 \\
$\sigma_{\mu}$ & 2.999 & 2.306 & 5.063 & 4.856 & 2.906 & 6.601 \\
$\sigma_{\alpha}$ & 0.876 & 0.774 & 1.023 & 0.661 & 0.595 & 0.749 \\
$\sigma_{\chi}$ & 2.107 & 1.443 & 4.506 & 6.813 & 5.525 & 9.484 \\
$\sigma_{R}$ & 0.202 & 0.177 & 0.233 & 0.234 & 0.154 & 0.198 \\
\hline \hline & & & & & & \\
\hline
\end{tabular}


Figure 1: Government Spending Shock: 1955Q4-1979Q4 Estimates (Loser Prior)
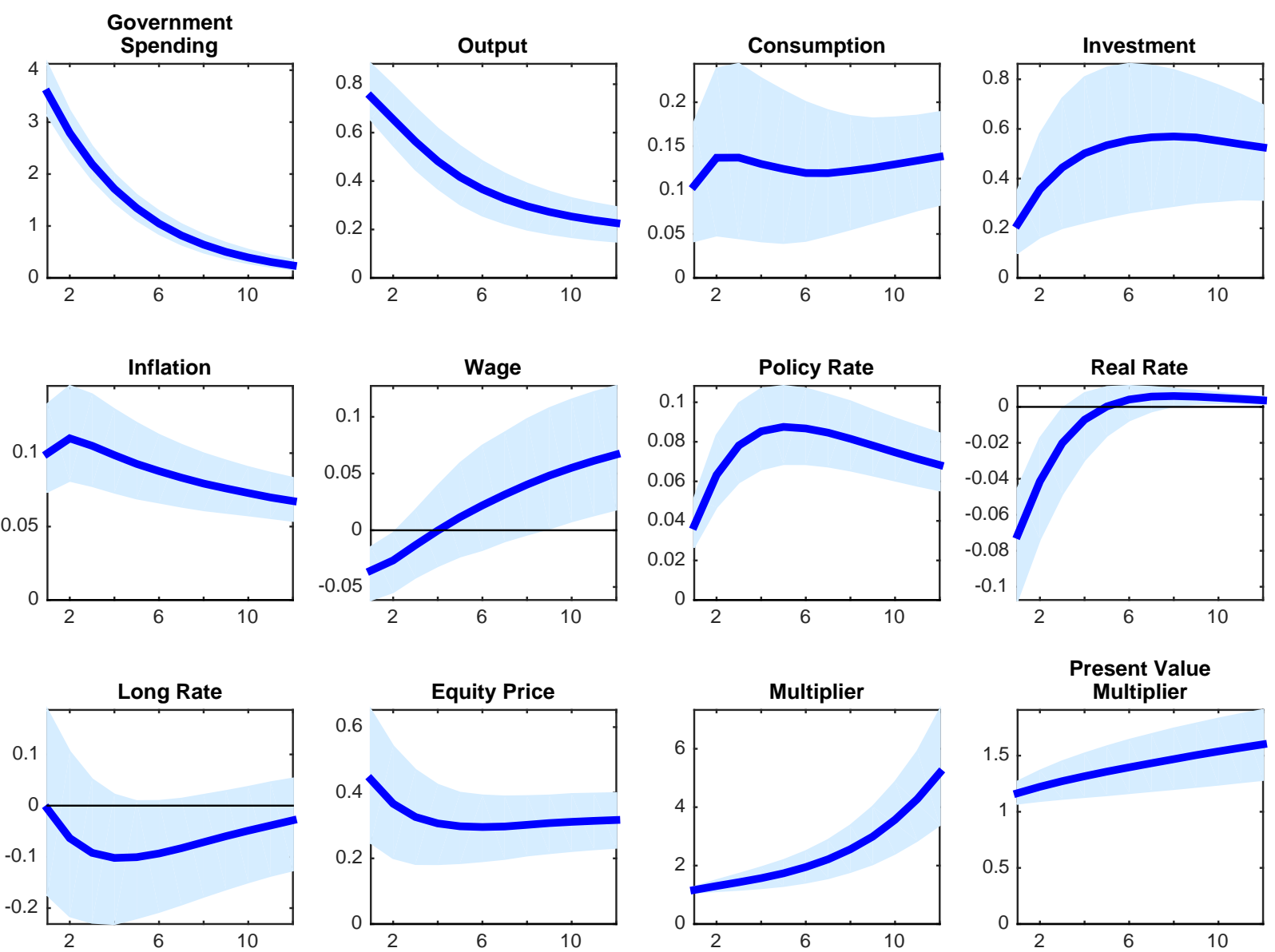

Notes: The solid line represents the pointwise median impulse response function, and the shaded area is the corresponding 5th and 95th percentiles of the posterior distribution. The horizontal axes are in quarters, the vertical axes are in percentage points. The multiplier is defined as $M_{i}=\frac{Y}{g} \frac{\hat{g}_{i}}{\hat{y}_{i}}$, and the present value multiplier is defined as $P V M_{i}=\frac{Y}{g} \frac{\sum_{j=0}^{i}\left(\prod_{k=0}^{i}\left(1+\hat{R}_{k}\right)^{-1}\right) \hat{g}_{j}}{\sum_{j=0}^{i}\left(\prod_{k=0}^{i}\left(1+\hat{R}_{k}\right)^{-1}\right) \hat{y_{j}}}$. 
Figure 2: Government Spending Shock: 1980Q1-2015Q4 Estimates (Loser Prior)
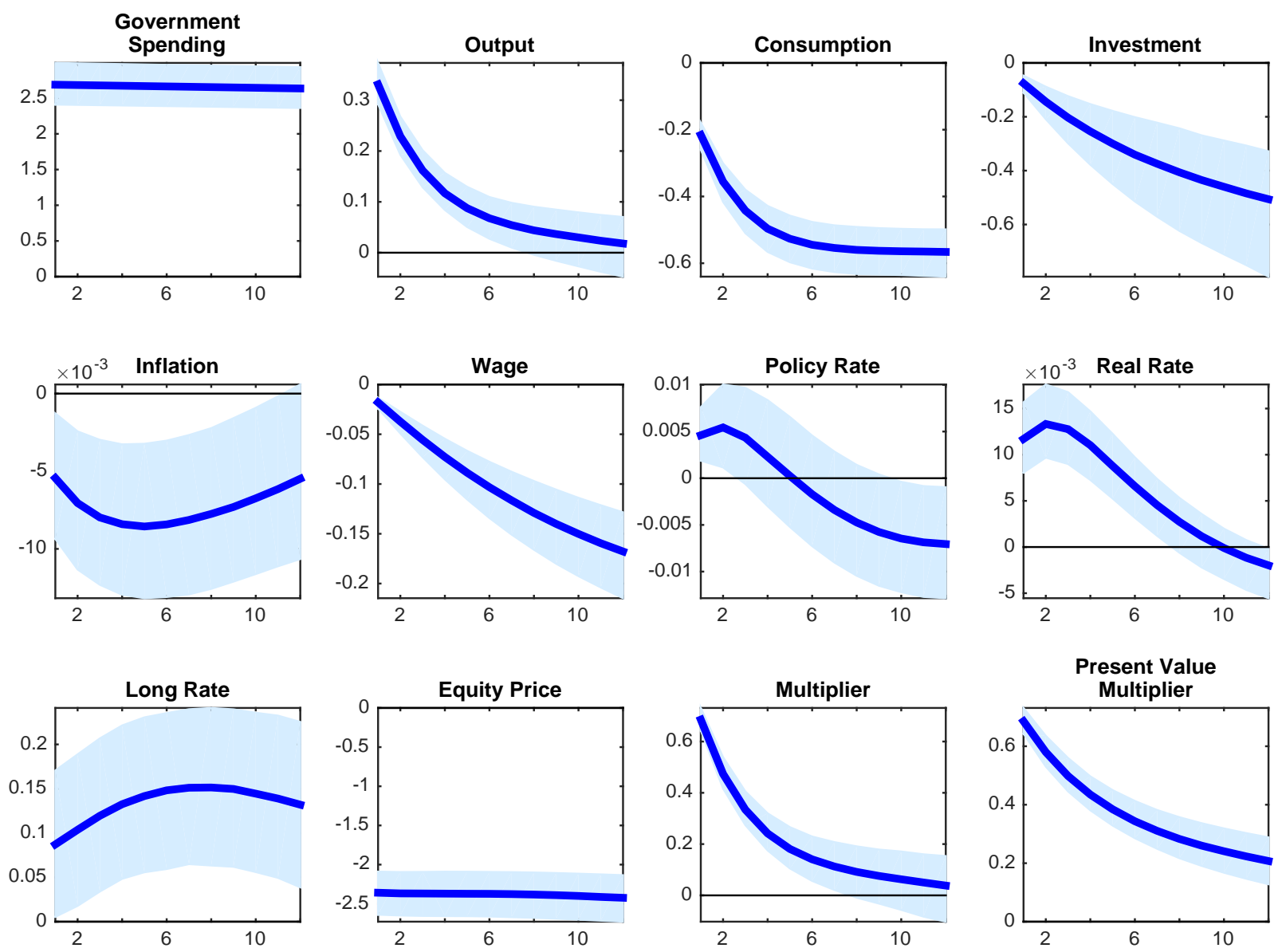

Notes: The solid line represents the pointwise median impulse response function, and the shaded area is the corresponding 5th and 95th percentiles of the posterior distribution. The horizontal axes are in quarters, the vertical axes are in percentage points. The multiplier is defined as $M_{i}=\frac{Y}{g} \frac{\hat{g}_{i}}{\hat{y}_{i}}$, and the present value multiplier is defined as $P V M_{i}=\frac{Y}{g} \frac{\sum_{j=0}^{i}\left(\prod_{k=0}^{i}\left(1+\hat{R}_{k}\right)^{-1}\right) \hat{g}_{j}}{\sum_{j=0}^{i}\left(\prod_{k=0}^{i}\left(1+\hat{R}_{k}\right)^{-1}\right) \hat{y}_{j}}$. 


\section{References}

Banbura, Marta, Domenico Giannone and Lucrezia Reichlin, 2010, Large Bayesian vector auto regressions, Journal of Applied Econometrics 25(1), 71-92.

Bansal, Ravi and Amir Yaron, 2004, Risks for the Long Run: A Potential Resolution of Asset Pricing Puzzles, The Journal of Finance 59(4), 1481-1509.

Bianchi, Francesco and Cosmin Ilut, 2014, Monetary/Fiscal Policy Mix and Agents' Beliefs, NBER Working Papers 20194, National Bureau of Economic Research, Inc.

Bianchi, Francesco and Leonardo Melosi, 2017, Escaping the Great Recession, American Economic Review forthcoming.

Blanchard, Olivier and Roberto Perotti, 2002, An Empirical Characterization of the Dynamic Effects of Changes in Government Spending and Taxes on Output, The Quarterly Journal of Economics 117(4), 1329-1368.

Campbell, John Y., 2003, Consumption-based asset pricing, in G.M. Constantinides, M. Harris and R. M. Stulz (editors), Handbook of the Economics of Finance, Vol. 1 of Handbook of the Economics of Finance, Elsevier, chapter 13, pp. 803-887.

Campbell, John Y., Carolin Pflueger and Luis M. Viceira, 2014, Monetary Policy Drivers of Bond and Equity Risks, NBER Working Papers 20070, National Bureau of Economic Research, Inc.

Campbell, John Y. and John Cochrane, 1999, Force of Habit: A Consumption-Based Explanation of Aggregate Stock Market Behavior, Journal of Political Economy 107(2), 205-251.

Christiano, Lawrence J., Martin S. Eichenbaum and Mathias Trabandt, 2016, Unemployment and Business Cycles, Econometrica 84, 1523-1569.

Christiano, Lawrence J., Mathias Trabandt and Karl Walentin, 2010, DSGE Models for Monetary Policy Analysis, in Benjamin M. Friedman and Michael Woodford (editors), Handbook of Monetary Economics, Vol. 3, pp. 285-367.

Christiano, Lawrence J., Mathias Trabandt and Karl Walentin, 2011, Introducing financial frictions and unemployment into a small open economy model, Journal of Economic Dynamics and Control 35(12), 1999-2041.

Christiano, Lawrence, Martin Eichenbaum and Charles Evans, 2005, Nominal Rigidities and the Dynamic Effects of a shock to Monetary Policy, Journal of Political Economy 113, 1-45.

Cogley, Timothy, Giorgio E. Primiceri and Thomas J. Sargent, 2010, Inflation-Gap Persistence in the US, American Economic Journal: Macroeconomics 2(1), 43-69.

Del Negro, Marco and Frank Schorfheide, 2008, Forming priors for DSGE models (and how it affects the assessment of nominal rigidities), Journal of Monetary Economics 55(7), 1191-1208.

Del Negro, Marco, Marc P. Giannoni and Frank Schorfheide, 2015, Inflation in the Great Recession and New Keynesian Models, American Economic Journal: Macroeconomics 7(1), 168-96. 
Erceg, Christopher J., Dale W. Henderson and Andrew T. Levin, 2000, Optimal monetary policy with staggered wage and price contracts, Journal of Monetary Economics 46(2), 281-313.

Jermann, Urban and Vincenzo Quadrini, 2012, Macroeconomic Effects of Financial Shocks, American Economic Review 102(1), 238-71.

Justiniano, Alejandro, Giorgio Primiceri and Andrea Tambalotti, 2010, Investment shocks and business cycles, Journal of Monetary Economics 57(2), 132-45.

Kliem, Martin, Alexander Kriwoluzky and Samad Sarferaz, 2016, Monetary?fiscal policy interaction and fiscal inflation: A tale of three countries, European Economic Review 88(C), 158-184.

Leeper, Eric M., 1991, Equilibria under 'active' and 'passive' monetary and fiscal policies, Journal of Monetary Economics 27(1), 129-147.

Leeper, Eric M., Michael Plante and Nora Traum, 2010, Dynamics of fiscal financing in the United States, Journal of Econometrics 156(2), 304-321.

Leeper, Eric M., Nora Traum and Todd B. Walker, 2015, Clearing Up the Fiscal Multiplier Morass: Prior and Posterior Analysis, NBER Working Papers 21433, National Bureau of Economic Research, Inc.

Liu, Zheng, Pengfei Wang and Tao Zha, 2013, Land-Price Dynamics and Macroeconomic Fluctuations, Econometrica 81(3), 1147-1184.

Lubik, Thomas A. and Frank Schorfheide, 2004, Testing for Indeterminacy: An Application to U.S. Monetary Policy, American Economic Review 94(1), 190-217.

Mertens, Karel and Morten O. Ravn, 2013, The Dynamic Effects of Personal and Corporate Income Tax Changes in the United States, American Economic Review 103(4), 1212-47.

Mertens, Karel and Morten O. Ravn, 2014, A reconciliation of SVAR and narrative estimates of tax multipliers, Journal of Monetary Economics 68(S), S1-S19.

Mountford, Andrew and Harald Uhlig, 2009, What are the effects of fiscal policy shocks?, Journal of Applied Econometrics 24(6), 960-992.

Newey, Whitney K. and Daniel McFadden, 1986, Large sample estimation and hypothesis testing, in R. F. Engle and D. McFadden (editors), Handbook of Econometrics, Vol. 4, pp. 2,111-245.

Perotti, Roberto, 2005, Estimating the effects of fiscal policy in OECD countries, Proceedings .

Smets, Frank and Rafael Wouters, 2007, Shocks and Frictions in US Business Cycles: a Bayesian DSGE Approach, American Economic Review 97, 586-606.

Stock, James H. and Mark W. Watson, 2008, Whats New in Econometrics- Time Series, Lecture 7, National Bureau of Economic Research, Inc.

Swanson, Eric, 2015, A Macroeconomic Model of Equities and Real, Nominal, and Defaultable Debt, Mimeo, University of California Irvine.

Theodoridis, Konstantinos, 2011, An efficient minimum distance estimator for DSGE models, Bank of England working papers 439, Bank of England. 
Trabandt, Mathias and Harald Uhlig, 2011, The Laffer curve revisited, Journal of Monetary Economics $\mathbf{5 8}(4), 305-327$.

Traum, Nora and Shu-Chun S. Yang, 2011, Monetary and fiscal policy interactions in the post-war U.S, European Economic Review 55(1), 140-164.

Uhlig, Harald, 2005, What are the effects of monetary policy on output? Results from an agnostic identification procedure, Journal of Monetary Economics 52(2), 381-419. 


\section{A DSGE Model}

\section{A.1 Stationary Equations}

$$
\begin{aligned}
& \frac{1}{C_{t}-h \frac{C_{t-1}}{\Gamma_{t}}}=\lambda_{t} \\
& \lambda_{t}=\beta \frac{R_{t}^{G} \lambda_{t+1}}{\Pi_{t+1} \Gamma_{t+1}} \\
& Y_{t}=L_{t}^{1-\phi}\left(v_{t} \frac{K_{t-1}}{\Gamma_{t}}\right)^{\phi} \\
& K_{t}=(1-\delta) \frac{K_{t-1}}{\Gamma_{t}}+\left(1-\phi_{I}\left(\frac{I_{t} \Gamma_{t}}{I_{t-1}}-\Gamma\right)^{Z_{t}}\right) I_{t} \\
& R_{t}^{K}\left(1-\tau_{t}\right)=u^{\prime}\left(v_{t}\right) \\
& q_{t}=\beta \frac{\lambda_{t+1}}{\lambda_{t} \Gamma_{t+1}}\left[\left\{\left(1-\tau_{t+1}\right) R_{t+1}^{K} v_{t+1}-u\left(v_{t+1}\right)\right\}+(1-\delta) q_{t+1}\right] \\
& 1=q_{t}\left\{1-\frac{\phi_{I}}{2}\left(\frac{I_{t} \Gamma_{t}}{I_{t-1}}-\Gamma\right)^{2}-\phi_{I}\left(\frac{I_{t} \Gamma_{t}}{I_{t-1}}-\Gamma\right) \frac{I_{t} \Gamma_{t}}{I_{t-1}}\right\}+\beta \frac{\lambda_{t+1}}{\lambda_{t} \Gamma_{t+1}} q_{t+1} \phi_{I}\left(\frac{I_{t+1} \Gamma_{t+1}}{I_{t}}-\Gamma\right)\left(\frac{I_{t+1} \Gamma_{t+1}}{I_{t}}\right)^{2} \\
& \Xi_{I, t}=Y_{t}-W_{t} L_{t}-R_{t}^{K} v_{t} \frac{K_{t-1}}{\Gamma_{t}} \\
& M C_{t}=\frac{W_{t}}{(1-\phi) \frac{Y_{t}}{L_{t}}} \\
& M C_{t}=\frac{R_{t}^{K} v_{t}}{\phi \frac{Y_{t} \Gamma_{t}}{K_{t-1}}}
\end{aligned}
$$




$$
\begin{aligned}
& F_{1, t}=\lambda_{t} M C_{t} Y_{t}^{d}+\beta \xi_{p} E_{t}\left(\frac{\Pi_{t}^{\kappa_{p}} \Pi^{1-\kappa_{p}}}{\Pi_{t+1}}\right)^{-\frac{\lambda_{p}}{\lambda_{p}-1}} F_{1, t+1} \\
& F_{2, t}=\lambda_{t} \bar{\Pi}_{t} Y_{t}^{d}+\beta \xi_{d} E_{t}\left(\frac{\Pi_{t}^{\kappa_{p}} \Pi^{1-\kappa_{p}}}{\Pi_{t+1}}\right)^{-\frac{1}{\lambda_{p}-1}}\left(\frac{\bar{\Pi}_{t}}{\bar{\Pi}_{t+1}}\right) F_{2, t+1} \\
& 0=\lambda_{p} F_{1, t}-F_{2, t} \\
& 1=\xi_{p}\left(\frac{\Pi_{t-1}^{\kappa_{p}} \Pi^{1-\kappa_{p}}}{\Pi_{t}}\right)^{-\frac{1}{\lambda_{p}-1}}+\left(1-\xi_{p}\right) \bar{\Pi}_{t}^{-\frac{1}{\lambda_{p}-1}} \\
& Y_{t}=\frac{C_{t}+I_{t}+G_{t}}{v_{t}^{p}} \\
& B_{t}+\tau_{t}\left(R_{t}^{K} v_{t} \frac{K_{t-1}}{\Gamma_{t}}+W_{t} L_{t}\right)=\frac{R_{t-1}^{G} B_{t-1}}{\Gamma_{t} \Pi_{t}}+G_{t} \\
& \tau_{t}=\rho_{\tau} \tau_{t-1}+\left(1-\rho_{\tau}\right) \phi_{\tau} \tau \frac{B_{t-1}}{Y_{t-1}} \\
& g_{t}=\rho_{g} g_{t-1}-\left(1-\rho_{g}\right) \phi_{g} g \frac{B_{t-1}}{Y_{t-1}}+\epsilon_{g, t} \\
& Y_{t}=C_{t}+I_{t}+G_{t}+u\left(v_{t}\right) \frac{K_{t-1}}{\Gamma_{t}} \\
& v_{t}=\tilde{\lambda}_{t} \frac{1}{\lambda_{w}}\left(w_{t}^{n e w}\right)^{\frac{1}{1-\lambda w}} w_{t}^{\frac{\lambda w}{\lambda_{w}-1}}\left(1-\tau_{t}\right) L_{t}^{d}+\beta \xi_{w} E_{t}\left(\frac{\Pi_{t}^{\iota w} \bar{\Pi}_{t+1}^{1-\iota w}}{\Pi_{t+1}}\right)^{\frac{1}{1-\lambda w}}\left(\frac{w_{t+1}^{n e w} \Gamma_{t+1}}{w_{t}^{n e w}}\right)^{\frac{1}{\lambda_{w}-1}} \\
& v_{t}=\chi_{t}\left(\frac{w_{t}}{w_{t}^{n e w}}\right)^{\frac{(1+\sigma) \lambda_{w}}{\lambda_{w}-1}}\left(L_{t}^{d}\right)^{1+\sigma}+\beta \xi_{w} E_{t}\left(\frac{\Pi_{t}^{\iota w} \bar{\Pi}_{t+1}^{1-\iota_{w}}}{\Pi_{t+1}}\right)^{\frac{(1+\sigma) \lambda w}{1-\lambda w}}\left(\frac{w_{t+1}^{n e w} \Gamma_{t+1}}{w_{t}^{n e w}}\right)^{\frac{(1+\sigma) \lambda_{w}}{\lambda_{w}-1}} v_{t+1} \\
& w_{t}^{\frac{1}{1-\lambda w}}=\xi_{w}\left(\frac{\Pi_{t-1}^{\iota w} \bar{\Pi}_{t}^{1-\iota_{w}}}{\Pi_{t}}\right)^{\frac{1}{1-\lambda_{w}}}\left(\frac{w_{t-1}}{\Gamma_{t}}\right)^{\frac{1}{1-\lambda w}}+\left(1-\xi_{w}\right)\left(w_{t}^{n e w}\right)^{\frac{1}{1-\lambda w}}
\end{aligned}
$$

\section{A.2 Steady-States}

$$
\begin{aligned}
& R=\frac{\Pi \Gamma}{\beta} \\
& R^{K}=\frac{\frac{\Gamma}{\beta}-(1-\delta)}{1-\tau}
\end{aligned}
$$




$$
u^{\prime}(1)=R^{K}(1-\tau)
$$

$$
\frac{Y \Gamma}{K}=\left(\frac{L}{Y}\right)^{\frac{1-\phi}{\phi}}
$$

$$
\begin{aligned}
M C & =\frac{R^{K}}{\phi \frac{Y \Gamma}{K}} \\
\frac{Y \Gamma}{K} & =\frac{R^{K}}{\phi M C} \\
\frac{L}{Y} & =\left(\frac{R^{K}}{\phi M C}\right)^{\frac{\phi}{1-\phi}}
\end{aligned}
$$$$
W=(1-\phi) M C \frac{Y}{L}
$$$$
W=(1-\phi) M C\left(\frac{R^{K}}{\phi M C}\right)^{-\frac{\phi}{1-\phi}}
$$

$$
Y=\frac{Y}{L} L
$$

$$
K=\frac{K}{Y \Gamma} Y \Gamma
$$

$$
I=\left(\frac{\Gamma-1+\delta}{\Gamma}\right) K
$$

$$
C=Y-I-G
$$

$$
\begin{aligned}
& \lambda=\frac{1}{\left(1-\frac{h}{\Gamma}\right) C} \\
& F_{1}=\frac{\lambda M C Y}{1-\beta \xi_{p}} \\
& F_{2}=\frac{\lambda Y}{1-\beta \xi_{p}}
\end{aligned}
$$




$$
\begin{aligned}
& v=\frac{\lambda w(1-\tau) L^{d}}{\left(1-\beta \xi_{w} \Gamma^{\frac{1}{\lambda_{w}-1}}\right) \lambda_{w}} \\
& \chi=\frac{v\left(1-\beta \xi_{w} \Gamma^{\frac{(1+\sigma) \lambda_{w}}{\lambda_{w}-1}} v\right)}{L^{1+\sigma}} \\
& B=\frac{B}{Y} Y \\
& \tau=\frac{\frac{R^{G}-\Gamma \Pi}{\Gamma \Pi} B+G}{\left(\frac{R^{K} K}{\Gamma}+W L\right)}
\end{aligned}
$$

\section{B Tables}

Table 6: Endogenous Variables: A

\begin{tabular}{l|l}
\hline \hline Mnemonic & Description \\
\hline \hline$C_{t}$ & Consumption \\
$Y_{t}$ & Output \\
$I_{t}$ & Investment \\
$g_{t}$ & Government Spending \\
$\tau_{t}$ & Taxes \\
$B_{t}$ & Government Debt \\
$\lambda_{t}$ & Marginal Utility \\
$Q_{t}$ & Tobins Q \\
$R_{t}^{k}$ & Rental Rate of Capital \\
$R_{t}$ & Policy Rate Growth \\
$K_{t}$ & Capital \\
$v_{t}$ & Capital Utilisation \\
$M_{t}$ & Marginal Cost \\
$F_{1, t}$ & Price Philips Curve Numerator \\
$F_{2, t}$ & Philips Curve Denominator \\
$\bar{\Pi}_{t}$ & Optimal Relative Price \\
$v_{t}^{p}$ & Price Dispersion \\
$w_{t}$ & Real Wage \\
$w_{t}^{n e w}$ & Optimal Wage \\
$v_{t}^{w}$ & Wage Dispersion \\
$\Pi_{t}$ & Inflation \\
$L_{t}$ & Hours \\
$v_{t}$ & Wage Philips Curve \\
$T R_{t}$ & Transfers \\
$\Gamma_{t}$ & Productivity Growth \\
$\hat{y}_{t}$ & Output Log Deviation from SS \\
$\Xi_{t}$ & Profits \\
$Q_{e, t}$ & Equity Price \\
$r_{t}$ & Real Rate \\
$\hat{\pi}_{t}$ & Inflation Log Deviation from SS \\
$\hat{R}_{t}$ & Policy Rate \\
\hline \hline &
\end{tabular}


Table 7: Endogenous Variables: B

\begin{tabular}{l|l}
\hline \hline Mnemonic & Description \\
\hline \hline$\hat{c}_{t}$ & Consumption Log Deviation from SS \\
$\hat{i}_{t}$ & Investment Log Deviation from SS \\
$\hat{q}_{t}^{F}$ & Equity Price Log Deviation from SS \\
$\hat{g}_{t}$ & Government Spending Log Deviation from SS \\
$\hat{r}_{t}$ & Real Rate from SS \\
$\psi_{t}$ & Risk Premium Exogenous Process \\
$\lambda_{p, t}$ & Price Markup Exogenous Process \\
$\lambda_{w, t}$ & Wage Markup Exogenous Process \\
$\mu_{t}$ & Investment Specific Productivity Exogenous Process \\
$\hat{w}_{t}$ & Wage Log Deviation from SS \\
$\Delta \hat{y}_{t}$ & Output Growth Log Deviation from SS \\
$\Delta \hat{c}_{t}$ & Consumption Growth Log Deviation from SS \\
$\Delta \hat{i}_{t}$ & Investment Growth Log Deviation from SS \\
$\Delta \hat{w}_{t}$ & Wage Growth Log Deviation from SS \\
$\hat{l}_{t}$ & Average Hours Log Deviation from SS \\
$\Delta \hat{g}_{t}$ & Government Consumption Growth Log Deviation from SS \\
$T_{\text {TaxRe }}$ & Tax Revenues \\
$\Delta T a x R e v_{t}$ & Tax Revenues Growth Log Deviation from SS \\
$\Delta \hat{b}_{t}$ & Government Debt Growth Log Deviation from SS \\
$\alpha_{t}$ & Stationary Productivity Process \\
$\theta_{p, t}$ & MA Price Markup Process \\
$\theta_{w, t}$ & MA Wage Markup Process \\
$q_{c, t}$ & Consumption Equity Price \\
$R_{c, t}$ & Consumption Equity Return \\
$\hat{q}_{c, t}$ & Consumption Equity Price Log Deviation from SS \\
$R_{L, t}$ & Long Term Interest Rate \\
$\bar{\pi}_{t}$ & Inflation Target Process \\
$\hat{\pi}_{A, t}$ & CPI Annual Inflation \\
$\chi_{t}$ & Labour Supply Process \\
\hline \hline
\end{tabular}

Table 8: Exogenous Variables

\begin{tabular}{l|l}
\hline \hline Mnemonic & Description \\
\hline \hline$\epsilon_{g, t}$ & Government Spending Shock \\
$\epsilon_{\gamma, t}$ & Non Stationary Productivity Shock \\
$\epsilon_{\psi, t}$ & Risk Premium Shock \\
$\epsilon_{R, t}$ & Monetary Policy Shock \\
$\epsilon_{\mu, t}$ & Investment Specific Productivity Shock \\
$\epsilon_{\chi, t}$ & Labour Supply Shock \\
$\epsilon_{\alpha, t}$ & Stationary Productivity Shock \\
\hline \hline
\end{tabular}




\section{Summary of Model Equations}

$$
\begin{aligned}
& \frac{\Gamma_{t}}{\Gamma}=\left(\frac{\Gamma_{t-1}}{\Gamma}\right)^{\rho_{\gamma}} \exp \left(\sigma_{\gamma} \epsilon_{\gamma_{t}}\right) \\
& \frac{1}{C_{t}-\frac{h C_{t-1}}{\Gamma_{t}}}=\lambda_{t}
\end{aligned}
$$

$$
\frac{\lambda_{t}}{\psi_{t}}=\frac{\beta R_{t} \lambda_{t+1}}{\Pi_{t+1} \Gamma_{t+1}}
$$

$$
Y_{t}=\alpha_{t}\left(\frac{L_{t}}{v^{w}}\right)^{1-\phi}\left(\frac{v_{t} K_{t-1}}{\Gamma_{t}}\right)^{\phi}
$$

$$
K_{t}=\frac{(1-\delta) K_{t-1}}{\Gamma_{t}}+I_{t} \mu_{t}\left(1-0.500 \chi_{I}\left(\frac{\Gamma_{t} I_{t}}{I_{t-1}}-\Gamma\right)^{2}\right)
$$

$$
R_{t}^{k}\left(1-\tau_{t}\right)=\kappa_{1}+\kappa_{2}\left(v_{t}-1\right)
$$

$$
Q_{t}=\frac{\beta \lambda_{t+1}}{\lambda_{t} \Gamma_{t+1}}\left(\left(1-\tau_{t+1}\right) R_{t+1}^{k} v_{t+1}-\kappa_{1}\left(v_{t+1}-1\right)-0.500 \kappa_{2}\left(v_{t+1}-1\right)^{2}+(1-\delta) Q_{t+1}\right)
$$

$$
1=\mu_{t} Q_{t}\left(1-0.500 \chi_{I}\left(\frac{\Gamma_{t} I_{t}}{I_{t-1}}-\Gamma\right)^{2}-\frac{\Gamma_{t} I_{t} \chi_{I}\left(\frac{\Gamma_{t} I_{t}}{I_{t-1}}-\Gamma\right)}{I_{t-1}}\right)+\chi_{I} \frac{\beta \lambda_{t+1}}{\lambda_{t} \Gamma_{t+1}} Q_{t+1} \mu_{t+1}\left(\frac{\Gamma_{t+1} I_{t+1}}{I_{t}}-\Gamma\right)\left(\frac{\Gamma_{t+1} I_{t+}}{I_{t}}\right.
$$

$$
\begin{aligned}
& M C_{t}=\frac{w_{t}}{(1-\phi) \frac{Y_{t}}{\frac{L_{t}}{v^{w}}}} \\
& M C_{t}=\frac{v_{t} R_{t}^{k}}{\frac{\Gamma_{t} \phi Y_{t}}{K_{t-1}}}
\end{aligned}
$$


$F_{1 t}=\frac{Y_{t} \lambda_{t} M C_{t}}{v^{p} t}+\beta \xi_{p}\left(\frac{\Pi_{t-1}^{\iota_{p}} \bar{\pi}_{t}^{1-\iota_{p}}}{\Pi_{t}}\right)^{\frac{\left(-\lambda_{p}\right)}{\lambda_{p}-1}} F_{1 t+1}$

$F_{2 t}=\frac{Y_{t} \lambda_{t} \bar{\Pi}_{t}}{v^{p} t}+\beta \xi_{p}\left(\frac{\Pi_{t-1}^{\iota_{p}} \bar{\pi}_{t}^{1-\iota_{p}}}{\Pi_{t}}\right)^{\frac{(-1)}{\lambda_{p}-1}} \frac{\bar{\Pi}_{t}}{\bar{\Pi}_{t+1}} F_{2 t+1}$

$0=F_{1 t} \lambda_{p}-F_{2 t}$

$1=\xi_{p}\left(\frac{\Pi_{t-1}^{\iota_{p}} \bar{\pi}_{t}^{1-\iota_{p}}}{\Pi_{t}}\right)^{\frac{(-1)}{\lambda_{p}-1}}+\left(1-\xi_{p}\right) \bar{\Pi}_{t}^{\frac{(-1)}{\lambda_{p}-1}}$

$v_{t}^{p}=\xi_{p}\left(\frac{\Pi_{t-1}^{\iota p} \bar{\pi}_{t}^{1-\iota_{p}}}{\Pi_{t}}\right)^{\frac{\left(-\lambda_{p}\right)}{\lambda_{p}-1}} v_{t-1}^{p}+\left(1-\xi_{p}\right) \bar{\Pi}_{t}^{\frac{\left(-\lambda_{p}\right)}{\lambda_{p}-1}}$

$\frac{Y_{t}}{v_{t}^{p}}=C_{t}+I_{t}+g_{t}+\kappa_{1}\left(v_{t}-1\right)+\frac{K_{t-1} 0.500 \kappa_{2}\left(v_{t}-1\right)^{2}}{\Gamma_{t}}$

$\frac{B_{t}}{\psi_{t}}+\tau_{t}\left(L_{t} w_{t}+\frac{K_{t-1} v_{t} R_{t}^{k}}{\Gamma_{t}}\right)=T R_{t}+g_{t}+\frac{R_{t-1} B_{t-1}}{\Gamma_{t} \Pi_{t}}$

$\frac{\tau_{t}}{\tau}=\left(\frac{\tau_{t-1}}{\tau}\right)^{\rho_{\tau}}\left(\frac{\frac{B_{t-1}}{Y_{t-1}}}{\frac{B}{Y}}\right)^{\left(1-\rho_{\tau}\right) \zeta_{\tau}}$

$\frac{g_{t}}{g}=\left(\frac{g_{t-1}}{g}\right)^{\rho_{g}} \exp \left(\sigma_{g} \epsilon_{g_{t}}\right)$

$v_{t}=\frac{L_{t}\left(1-\tau_{t}\right) \frac{\lambda_{t}}{\lambda_{w}} w^{n e w^{\frac{1}{1-\lambda}}} w_{t}^{\frac{\lambda w}{\lambda w-1}}}{v^{w}}+\beta \xi_{w}\left(\frac{\Pi_{t}^{\iota w} \bar{\pi}_{t}^{1-\iota w}}{\Pi_{t+1}}\right)^{\frac{1}{1-\lambda_{w}}}\left(\frac{\Gamma_{t+1} w^{n e w} t+1}{\Gamma_{t} w^{n e w} t}\right)^{\frac{1}{\lambda w-1}} v_{t+1}$ 


$$
v_{t}=\chi_{t}\left(\frac{w_{t}}{w^{n e w_{t}}}\right)^{\frac{\left(1+\sigma_{L}\right) \lambda_{w}}{\lambda_{w}-1}}\left(\frac{L_{t}}{v^{w_{t}}}\right)^{1+\sigma_{L}}+v_{t+1} \beta \xi_{w}\left(\frac{\Pi_{t}^{\iota_{w}} \bar{\pi}_{t}^{1-\iota_{w}}}{\Pi_{t+1}}\right)^{\frac{\left(1+\sigma_{L}\right) \lambda_{w}}{1-\lambda_{w}}}\left(\frac{\Gamma_{t+1} w^{n e w} t+1}{\Gamma_{t} w^{n e w}}\right)^{\frac{\left(1+\sigma_{L}\right) \lambda_{w}}{\lambda_{w}-1}}
$$

$1=\xi_{w}\left(\frac{\bar{\pi}_{t}^{1-\iota_{w}} \Pi_{t-1}^{\iota w}}{\Pi_{t}}\right)^{\frac{1}{1-\lambda w}}\left(\frac{w_{t-1}}{w_{t}} \frac{\Gamma_{t-1}}{\Gamma_{t}}\right)^{\frac{1}{1-\lambda_{w}}}+\left(1-\xi_{w}\right)\left(\frac{w^{n e w} t}{w_{t}}\right)^{\frac{1}{1-\lambda w}}$

$v_{t}^{w}=\xi_{w}\left(\frac{\bar{\pi}_{t}^{1-\iota_{w}} \Pi_{t-1}^{\iota w}}{\Pi_{t}}\right)^{\frac{\lambda_{w}}{1-\lambda_{w}}}\left(\frac{w_{t-1}}{w_{t}} \frac{\Gamma_{t-1}}{\Gamma_{t}}\right)^{\frac{\lambda_{w}}{1-\lambda_{w}}} v_{t-1}^{w}+\left(1-\xi_{w}\right)\left(\frac{w^{n e w} t}{w_{t}}\right)^{\frac{\lambda_{w}}{1-\lambda_{w}}}$

$\frac{R_{t}}{\frac{R \exp \left(\bar{\pi}_{t}\right)}{\Pi}}=\left(\frac{R_{t-1}}{\frac{R \exp \left(\bar{\pi}_{t-1}\right)}{\Pi}}\right)^{\rho_{R}}\left(\frac{\Pi_{t}}{\exp \left(\bar{\pi}_{t}\right)}\right)^{\left(1-\rho_{R}\right) \gamma_{\pi}}\left(\frac{Y_{t}}{Y}\right)^{\left(1-\rho_{R}\right) \gamma_{y}} \exp \left(\sigma_{R} \epsilon_{R, t}\right)$

$\Xi_{t}=\frac{Y_{t}}{v_{t}^{p}}-\frac{L_{t} w_{t}}{v_{t}^{w}}-\frac{K_{t-1} v_{t} R^{k}}{\Gamma_{t}}$

$Q_{e, t}=\frac{\beta \lambda_{t+1}}{\Gamma_{t} \lambda_{t}}\left(Q_{e, t+1}+\Xi_{t+1}\right)$

$r_{t}=\frac{R_{t}}{\Pi_{t+1}}$

$\hat{y}_{t}=\log \left(\frac{Y_{t}}{Y}\right)$

$\hat{\pi}_{t}=\log \left(\Pi_{t}\right)$

$\hat{R}_{t}=\log \left(\frac{R_{t}}{R}\right)+100(R-1)$

$\hat{c}_{t}=\log \left(\frac{C_{t}}{c}\right)$ 
$\hat{i}_{t}=\log \left(\frac{I_{t}}{i}\right)$

$\hat{q}_{t}^{F}=\log \left(\frac{Q_{e, t}}{Q_{e}}\right)$

$\hat{g}_{t}=\log \left(\frac{g_{t}}{g}\right)$

$\hat{r}_{t}=\log \left(\frac{r_{t}}{R}\right)$

$\hat{w}_{t}=\log \left(\frac{w_{t}}{w}\right)$

$\mu_{t}=\mu_{t-1}^{\rho_{\mu}} \exp \left(\sigma_{\mu} \epsilon_{\mu, t}\right)$

$\Delta \hat{y}_{t}=\gamma+\log \left(\frac{\frac{\Gamma_{t}}{\Gamma} Y_{t}}{Y_{t-1}}\right)$

$\Delta \hat{c}_{t}=\gamma+\log \left(\frac{\frac{\Gamma_{t}}{\Gamma} C_{t}}{C_{t-1}}\right)$

$\Delta \hat{i}_{t}=\gamma+\log \left(\frac{\frac{\Gamma_{t}}{\Gamma} I_{t}}{I_{t-1}}\right)$

$\Delta \hat{w}_{t}=\gamma+\log \left(\frac{\frac{\Gamma_{t}}{\Gamma} w_{t}}{w_{t-1}}\right)$

$\hat{l}_{t}=\log \left(\frac{L_{t}}{L}\right)$

$\Delta \hat{g}_{t}=\gamma+\log \left(\frac{\frac{\Gamma_{t}}{\Gamma} g_{t}}{g_{t-1}}\right)$ 
$\operatorname{TaxRev}_{t}=\tau_{t}\left(L_{t} w_{t}+\frac{K_{t-1} v_{t} R_{t}^{k}}{\Gamma_{t}}\right)$

$\Delta \widehat{\operatorname{TaxRe}} v_{t}=\gamma+\log \left(\frac{\frac{\Gamma_{t}}{\Gamma} \widehat{\operatorname{TaxRe} v_{t}}}{\widehat{\operatorname{TaxRe} v_{t-1}}}\right)$

$\Delta \hat{b}_{t}=\gamma+\log \left(\frac{\frac{\Gamma_{t}}{\Gamma} B_{t}}{B_{t-1}}\right)$

$\alpha_{t}=\alpha_{t-1}^{\rho_{\alpha}} \exp \left(\sigma_{\alpha} \epsilon_{\alpha, t}\right)$

$\chi_{t}=\chi_{t-1}^{\rho_{\chi}} \exp \left(\sigma_{\chi} \epsilon_{\chi, t}\right)$

$q_{c, t}=\frac{\beta \lambda_{t+1}}{\Gamma_{t} \lambda_{t}}\left(C_{t+1}^{\vartheta}+q_{c, t+1}\right)$

$R_{c, t}=\frac{q_{c, t}+C_{t}^{\vartheta}}{q_{c, t-1}}$

$\hat{q}_{c, t}=\log \left(\frac{q_{c, t}}{q_{c}}\right)$ 